\title{
Application of Magnetic and Dielectric Nanofluids for Electromagnetic-Assistance Enhanced Oil Recovery: A Review
}

\author{
Yarima Mudassir Hassan ${ }^{1, *}$, Beh Hoe Guan ${ }^{1, *}$, Hasnah Mohd Zaid ${ }^{1}$, Mohammed Falalu Hamza ${ }^{2}$, \\ Muhammad Adil ${ }^{1}$ (D), Abdullahi Abbas Adam 1,3 (iD) and Kurnia Hastuti 4 \\ 1 Department of Fundamental and Applied Sciences, Universiti Teknologi Petronas, \\ Bandar Seri Iskandar 31750, Malaysia; hasnamz@utp.edu.my (H.M.Z.); \\ muhammadadil86@hotmail.com (M.A.); abbas_20000289@utp.edu.my (A.A.A.) \\ 2 Department of Pure \& Industrial Chemistry, College of Natural and Physical Sciences, \\ Bayero University Kano, 3011 Kano, Nigeria; mfhamza.chm@buk.edu.ng \\ 3 Department of Physics, Al-Qalam University Katsina, 820252 Katsina, Nigeria \\ 4 Department of Mechanical Engineering, Faculty of Engineering, Universitas Islam Riau, \\ Riau 28284, Indonesia; Kurnia@eng.uir.ac.id \\ * Correspondence: mudassir_18003220@utp.edu.my (Y.M.H.); beh.hoeguan@utp.edu.my (B.H.G.)
}

Citation: Hassan, Y.M.; Guan, B.H.; Zaid, H.M.; Hamza, M.F.; Adil, M.; Adam, A.A.; Hastuti, K. Application of Magnetic and Dielectric Nanofluids for Electromagnetic-Assistance Enhanced Oil Recovery: A Review. Crystals 2021, 11, 106. https:// doi.org/10.3390/cryst11020106

Received: 3 December 2020 Accepted: 4 January 2021 Published: 26 January 2021

Publisher's Note: MDPI stays neutral with regard to jurisdictional clai$\mathrm{ms}$ in published maps and institutional affiliations.

Copyright: (C) 2021 by the authors. Licensee MDPI, Basel, Switzerland. This article is an open access article distributed under the terms and conditions of the Creative Commons Attribution (CC BY) license (https:// creativecommons.org/licenses/by/ $4.0 /)$.
Abstract: Crude oil has been one of the most important natural resources since 1856, which was the first time a world refinery was constructed. However, the problem associated with trapped oil in the reservoir is a global concern. Consequently, Enhanced Oil Recovery (EOR) is a modern technique used to improve oil productivity that is being intensively studied. Nanoparticles (NPs) exhibited exceptional outcomes when applied in various sectors including oil and gas industries. The harshness of the reservoir situations disturbs the effective transformations of the NPs in which the particles tend to agglomerate and consequently leads to the discrimination of the NPs and their being trapped in the rock pores of the reservoir. Hence, Electromagnetic-Assisted nanofluids are very consequential in supporting the effective performance of the nanoflooding process. Several studies have shown considerable incremental oil recovery factors by employing magnetic and dielectric NPs assisted by electromagnetic radiation. This is attributed to the fact that the injected nanofluids absorb energy disaffected from the EM source, which changes the fluid mobility by creating disruptions within the fluid's interface and allowing trapped oil to be released. This paper attempts to review the experimental work conducted via electromagnetic activation of magnetic and dielectric nanofluids for EOR and to analyze the effect of EM-assisted nanofluids on parameters such as sweeping efficiency, Interfacial tension, and wettability alteration. The current study is very significant in providing a comprehensive analysis and review of the role played by EM-assisted nanofluids to improve laboratory experiments as one of the substantial prerequisites in optimizing the process of the field application for EOR in the future.

Keywords: electromagnetic fields; magnetic nanofluids; dielectric nanofluids; enhanced oil recovery; core flooding

\section{Introduction}

It has been projected that the world's energy consumption will increase to $50 \%$ above the current level by the year 2050 [1]. This is a great challenge that needs to be given due consideration, because oil resources were regarded as the leading energy source in the world, and such anticipation was made before the outbreak of the coronavirus pandemic, which has contributed immensely to the fantastical deterioration of oil production globally. This shows that the process of oil extraction from the reservoir needs to be improved so that more oils can be produced. Oil reservoirs worldwide are experiencing persistent problems in terms of the extractability of the available natural resources in the oil fields. About two-thirds of the residual oil (75\%) cannot be recovered by employing traditional extraction 
procedures [2]. Enhanced Oil Recovery (EOR), also known as tertiary recovery, refers to the methods of extracting crude oil from a reservoir that is left behind after primary and secondary recovery. Primary recovery is the oil production process that relies on the natural movement of the oil within the underground pressure. This is attributed to some factors that stabilized the system, such as the expansion of the natural gas at the top surface of the reservoir. Secondary recovery, on the other hand, is the method of supplying external energy to the reservoir by injecting water or gas $\left(\mathrm{CO}_{2}\right)$ to increase reservoir pressure, as a result of which more oil can be produced. Therefore, EOR is more needed in the current situation than ever before due to the increasing global energy demand, and also considering the fact that oil production was observed to have been drastically reduced since 1995 [3]. Lack of EOR technology execution in oil extraction can be the downfall of a country in terms of oil production, Indonesia being one of the examples [3].

EOR has fundamentally relied upon three different techniques. The first one is thermal, which deals with heating the crude oil to reduce oil viscosity, as a result of which the mobility ratio will be improved. Heating reservoirs also can stimulate oil permeability and at the same time surface tension will equally reduce. Gas miscible flooding is the second method, in which hydrocarbon gases, $\mathrm{CO}_{2}$, nitrogen, or natural gases are injected into the reservoir, which results in reducing the oil viscosity. Chemical injection is the third category, which deals with injecting various chemicals such as polymers and surfactants into the reservoir, which can improve interfacial tension (IFT) reductions, emulsification, and wettability alterations which are worthy of oil stimulations. However, when utilizing these methods, still some persistent problems hinder the success of the process. As an example in the thermal method, there are challenges associated with heat leakage, the poor thermal conductivity of fluids, and a high energy cost [4]. Chemical injections into the reservoir, on the other hand, require a huge amount of chemicals to be employed, which is very expensive, and a lot of damage formations were reported for chemical injections in many instances [5,6]. Additionally, for gas miscible flooding, there is a persistent challenge associated with corrosions caused by $\mathrm{CO}_{2}$, high penetration of the injected gas from the injection well toward the production well that consequently renders a huge amount of oil to remain unrecovered $[7,8]$. Subsequently, nanoparticles (NPs) in the form of nanofluids flooding were proposed and were observed as the most advanced method, less expensive, and more efficient, which have been used over the years. However, still, there is a challenge for the active participation of the nanofluids because the fluids usually were activated by the brine, and brine has limited capacity in reducing interfacial tension. Recently, electrical resistive heating was proposed, in which the energy is carried by the electric field that can be disaffected when two electrodes connected to the AC source are positioned within the reservoir at a certain distance $[9,10]$. There are some challenges for this approach also, because the electrodes need to be drilled into the reservoir to communicate with hydrocarbons and therefore the installation of the antenna in the reservoir well is very difficult $[11,12]$. Hence, a different approach that is very effective, significant, less expensive, and environmentally feasible is highly needed, which will be better prepared if nanofluids flooding is going to be improved. Alternatively, the EM-assisted nanoflooding method tends to perform significantly and exclusively in this regard, because the nanofluid's mobility can be activated.

Water flooding was used in recent decades to recover the trapped oil in reservoir rocks; however, a large amount of crude oil remained unrecovered due to the high viscosity of the crude oil and low viscosity of the injected water. Consequently, this has necessitated the introduction of chemical flooding, which has performed soundly for recovering residual crude oil and has been employed extensively [13-15]. The fluid injection of alkaline, polymer, and surfactant are the most common chemicals employed for EOR. Different chemicals have different functions concerning EOR: for example, polymer flooding usually favors improving the mobility of the injected fluids [16], while IFT reduction and wettability alteration were observed during surfactant flooding [14]. Courageously, recent investigation has verified that combining nanoparticles with chemicals during the flooding process has 
prevailed a significant outcome over bare chemically flooding injections $[13,17,18]$. Furthermore, nano-Polymer or nano-surfactant flooding was considered as one of the successful chemical floodings that contain either NPs with polymers or NPs with surfactant which was found to be highly applicable in EOR [17]. However, a combination of all (NPs, polymer, and surfactant), termed nano-polymer-surfactant flooding, was recently proposed by some researchers, and satisfactory outcomes concerning improving oil productivity were reported [16].

Different hydrocarbon compounds exist in crude oil, such as asphaltenes, resins, aromatic, and waxes; the heaviest crude oil component with a complex nature of molecules is asphaltene, which is why the molecular structure of this component is not clearly understood [19-21]. Asphaltenes deposition on the surface of the reservoir rocks is disastrous for the productivity of the hydrocarbons [22]; this is attributed to the fact that the molecules of asphaltene tend to aggregate, and consequently, huge agglomerations will form. Complete removal of deposition of asphaltene from reservoir rock will cost a lot; alternatively, the asphaltene deposition was desired and recommended to be inhibited [19]. Asphaltene tends to accumulate at solid to liquid or liquid to liquid interfaces during the chemical flooding process, as a result of which microemulsions are formed due to IFT reductions and wettability change of the solid surface [23]. More studies are anticipated in the future for better clarifications of this mechanism. While investigation of asphaltene-brine interaction is still ongoing, some studies were made with dissimilar opinions, whereby some researchers advocated that the presence of water microemulsions has no significant effect on the precipitation and deposition of the asphaltene [24,25], whereas the others recommended that asphaltene deposition and aggregation were observed to reluctantly act in the presence of water, and also that the asphaltenes solubility was equally found to have increased when water was present $[26,27]$.

Many researchers have emphasized over the years the idea that the transformation from microparticles to a smaller particle will significantly provide new developments in many industries. Nanoparticles are eminent as a new field of science and technology that has been found to have numerous applications in different fields in modern science and technology [28]. The discipline that deals with the behavior of materials at the nano-scale level is termed nanoscience [29], whereas nanotechnology deals with issues associated with characterization, designing, production, and application of materials at the nanometer scale [29]. Nanoparticles (NPs) are particles with a diameter of less than 100 nanometers $(\mathrm{nm})$ in size, which have contributed to various sectors such as agriculture, biomedical, electronics, engineering, industries, etc. [30,31]. The reactions of the particles (such as mechanical, chemical, electrical, magnetic, etc.) perform well and preferably at the nanomaterial scale [32]. Nanoparticles have also contributed to almost all sectors in the oil and gas industry such as drilling, reservoir characterization, exploration, refining, production, etc. [33]. Furthermore, adding NPs into various fluids-based materials was found to have recovered more oil $[15,34]$. This is accredited to the fact that the injected NPs in a reservoir in the forms of nanofluids was observed to have altered some reservoir properties which in turn improved EOR; such factors include mobility ratio improvements, rock wettability alteration, improving quality of the injecting fluid, viscosity change of the injecting fluid, improvement for the interactions between rock surface and oil, conductivity and specific heat improvement, density change with regards to the injecting fluid, and emulsification improvement [17,35-38]. The smaller size and greater surface per unit volume of the NPs provide special and unique properties and granted the NPs the opportunity of flowing in the reservoir rock without being absorbed or withheld by any obstacle; as a result of that, they can deeply penetrate a very long distance through rock pores within the reservoir and execute the required task adequately [39].

Metal nanoparticles are NPs for pure metals (e.g., gold, zinc, etc.) or their compounds (e.g., oxides, sulfide, etc.). The first person who investigated the existence of metallic NPs in solution was Faraday in 1857; subsequently, the varieties of their colors were expressed by Mie for the first time in 1908 [40]. Investigation of metal oxide nanoparticles has been 
developed very rapidly and tremendously from the 1990s to date with satisfactory outcomes in various fields [3]. This has aroused and sustains the interest of many researchers performing different experiments and theoretical analyses using metal oxide NPs based on the excellence and exclusiveness observed in their performance in various fields, including the oil sector. Moreover, the application of metal oxide NPs was reported to have improved oil recovery by reducing the viscosity of the heavy oil or acting as a catalyst $[18,41]$. Besides oil and gas industrial applications, metal oxides NPs contributed to various fields of science and technology, such as physics, chemistry, and material sciences [42-44].

For about 10 years to date, several experimental analyses have been studied by employing some metal oxide nanofluids for EM-assisted EOR, which was found to be significant in recovering trapped oil from the porous media. Therefore, this is a new technology that was proposed for EOR within the last decades. This article will summarize the fundamental concepts and rationale behind this important initiative. Moreover, the published result concerning the activation of nanofluids via electromagnetic waves radiation will be summarized, and the influential role they played in bringing some alteration of the parameters that improve oil recovery will be analyzed. The effectiveness displayed by different dielectric and magnetic NPs on EOR will be summarized, discussed, compared, and evaluated. Some factors that constrain the effective performance of the NPs concerning EOR and possible ways that are preferable and worthy of recommendations to improve in the future time will be addressed.

\section{Oil Displacement Mechanisms Using Nanoparticles}

\subsection{Mobility Ratio Improvement}

Mobility ratio is the process of restructuring the flow of crude oil as a result of injecting fluids into the reservoir. Some factors that need to be taken into consideration before the fluid injection are flow rate, permeability, reservoir thickness, and fluids density. Mobility ratio can be achieved by decreasing the viscosity of the crude oil or increasing the viscosity of the injected fluids [45]. A large amount of oil is usually trapped in the reservoir rock pores after water flooding due to some forces (viscous, gravitational, and capillary) exerted upon the oil ganglion, which constrains the effective mobility of the oil. Consequently, the strong attraction of such forces on oil has to be regulated for the attainment or achievement of oil recovery, which could be successively achieved using different NPs, e.g., ZnO [45,46], $\mathrm{Al}_{2} \mathrm{O}_{3}$ [45], etc. The mobility ratio can be express in Equation (1) [45]:

$$
\mathrm{M}=\frac{\lambda_{i}}{\lambda_{o}}=\frac{K_{r i} / \mu_{i}}{K_{r o} / \mu_{o}}=\frac{K_{r i} \mu_{o}}{K_{r o} \mu_{i}}
$$

where $\lambda_{i}$ and $\lambda_{o}$ represent mobility of the injected fluids and oil, respectively, $K_{r i}$ the relative permeability of the injected fluid, $K_{r o}$ the relative permeability of the oil, and $\mu_{0}$ and $\mu_{i}$ the viscosity of the oil and injected fluids, respectively.

\subsection{Interfacial Tension (IFT) Reduction}

Interfacial tension (IFT) is regarded as one of the key parameters that were used to determine the smooth mobility and distribution of the fluids in porous media. This is the method that has to do with the fluid to fluid contact relationship in the reservoir, which is attributed to the existing force that needs to be reduced for the effective movement of the oil. The aim of measuring the IFT between oil, water, and injected fluids is to evaluate their effectiveness on EOR applications. Lowering IFT or increasing the viscosity of the injected fluids can be used to attain the incremental stage of the capillary number, which can lead to oil recovery. See Equation (2) [47]:

$$
\mathrm{Ncap}=\frac{v \mu}{\gamma}
$$

where $v$ represents Darcy velocity in $\mathrm{m} / \mathrm{s}, \mu$ viscosity of the injected phase, and $\gamma$ the interfacial tension (IFT) of the oil phase in $\mathrm{N} / \mathrm{m}$. 
The required energy to remove a particle from a fluid-fluid boundary $\mathrm{E}$ is given by the expression in Equation (3) [48]

$$
\mathrm{E}=\pi r^{2} \gamma \alpha \beta(1 \pm \cos \theta)
$$

where $r$ represents the radius of the particles, $\gamma \alpha \beta$ is the interfacial tension between the fluids, $\theta$ is the contact angle.

Significantly, NPs are considered as the potential candidate responsible for IFT reduction in porous media. For example, hydrophilic NPs dispersed in brine reduced IFT from 14.7 to $9.3 \mathrm{mN} / \mathrm{m}$ [48]. $\mathrm{ZnO}$ was dispersed in brine and reduced IFT from 13.38 to $11.60 \mathrm{mN} / \mathrm{m}$ [49]. $\mathrm{Fe}_{2} \mathrm{O}_{3}$ were dispersed in propanol and reduced IFT from 38.50 to $2.75 \mathrm{mN} / \mathrm{m}$ [2]. $\mathrm{Al}_{2} \mathrm{O}_{3}$ were dispersed in propanol and reduced IFT from 38.50 to $2.25 \mathrm{mN} / \mathrm{m}$ [2]. Furthermore, NPs concentration was reported to influence IFT improvement [50]; hydrophilic NPs concentration was increased from $0.01 \mathrm{wt}$. \% to $0.05 \mathrm{wt}$. \%, which was found to have decreased the IFT from 9.3 to $5.2 \mathrm{mN} / \mathrm{m} \mathrm{[51]}$

Goniometer can be used to measure IFT and wettability, as shown in Figure 1; however, the pendant drop method is the method that is most commonly used in the laboratory experiment for measuring the IFT between the injected fluid and the crude oil $[52,53]$. The apparatus consists of a light source, experimental cell, microscopic camera, and data acquisition system which were used for reading the IFT value. The IFT can be calculated from the subsequent shape of the oil droplet using the camera and computer, as illustrated in Figure 1 [49].

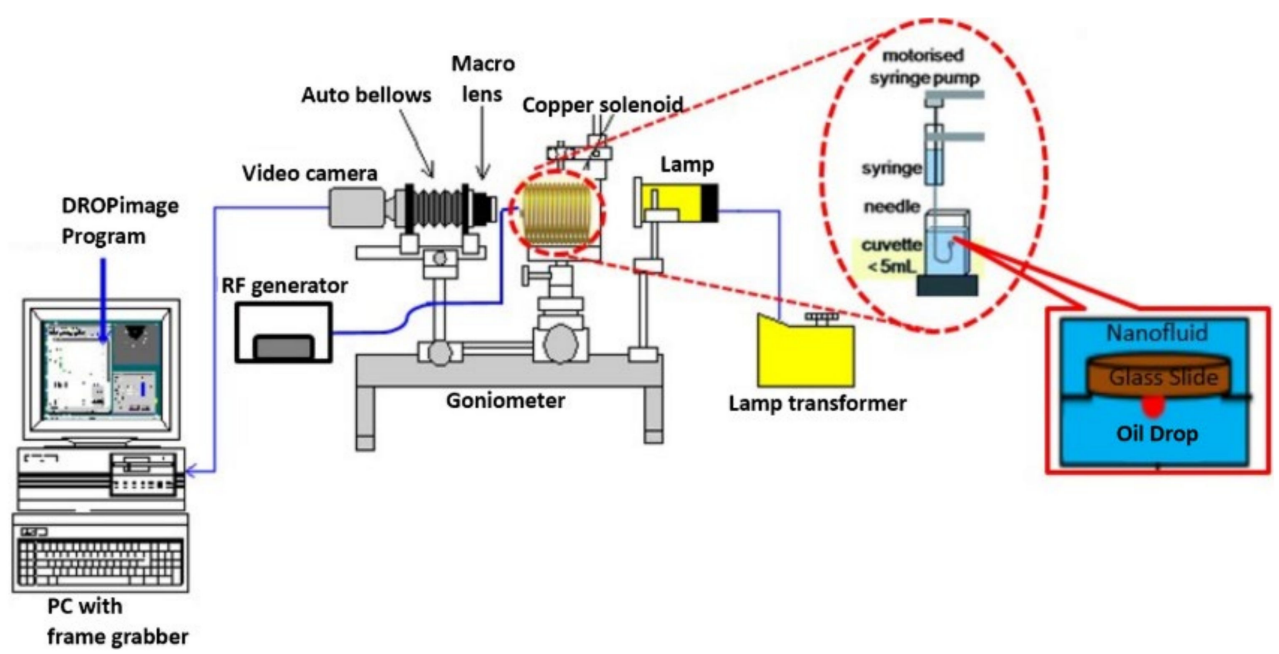

Figure 1. Goniometer is attached with an Electromagnetic source for the measurement of interfacial tension (IFT) and contact angle; source: Adil et al. [49].

\subsection{Wettability Alteration}

Wettability is defined as the tendency of one fluid to spread over a solid surface in the presence of another immiscible existing fluid. Moreover, reservoir rock is usually found to be in an oil-wet state, which provides some drawbacks for the successful transportation of the fluids. Consequently, restoring the reservoir rock situation from oil-wet to water-wet will provide a significant improvement in which the trapped oil in the rock pores can be released. Contact angle measurement is the most common method used for evaluating wettability. Different NPs were reported to have contributed immensely in changing the contact angle by making the angle to be either 90 (i.e., neutral wettability) or water wet (less than 90), as illustrated in Figures 2 and 3; some of such NPs are; ZnO [45,46,49,54], $\mathrm{Fe}_{2} \mathrm{O}_{3} / \mathrm{Fe}_{2} \mathrm{O}_{4}$ [2,55], $\mathrm{Al}_{2} \mathrm{O}_{3}[2,44,51,56], \mathrm{TiO}_{2}$ [44,51], $\mathrm{SiO}_{2}$ [44,51], $\mathrm{ZrO}_{2}$ [56], etc. For the 
three different phases (e.g., crude oil, brine, and injected fluids), the IFT can be determined by Young's law, as illustrated in Equation (4) [57]:

$$
\cos \theta=\frac{\sigma_{s w}-\sigma_{s o}}{\sigma_{w o}}
$$

where $\theta$ represents contact angle, $\sigma$ represents interfacial tensions (IFT), $\sigma$ ss $w$ stands for the IFT of solid-water, $\sigma$ so the IFT of solid-oil, and $\sigma w o$ the IFT of water-oil interfaces. Table 1 summarizes some available literature on the influence of NPs on IFT and wettability alteration.

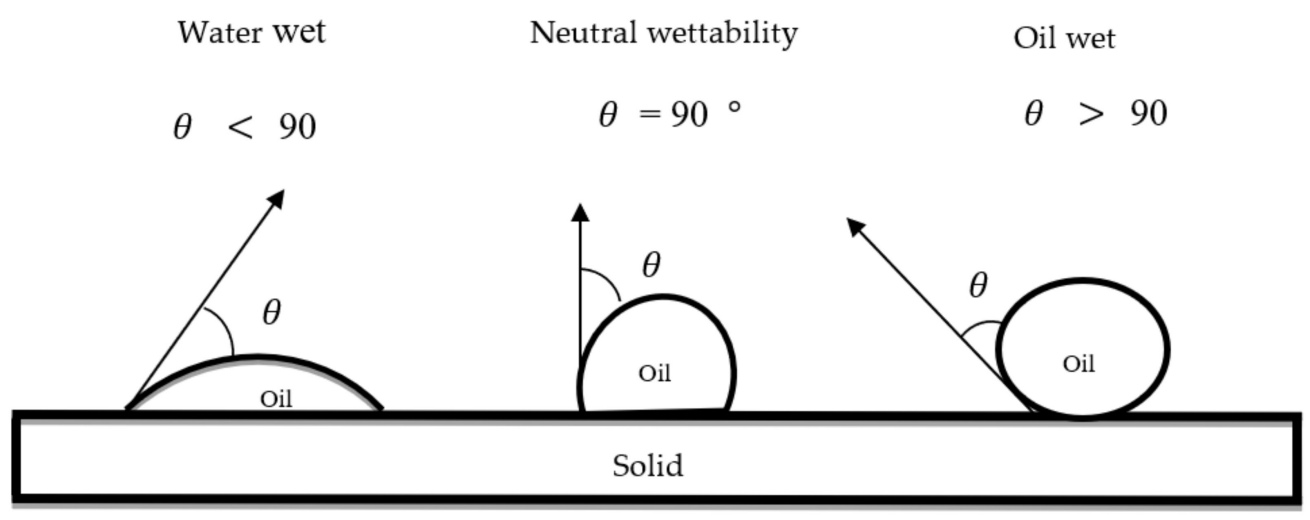

Figure 2. Wettability of rock surface.
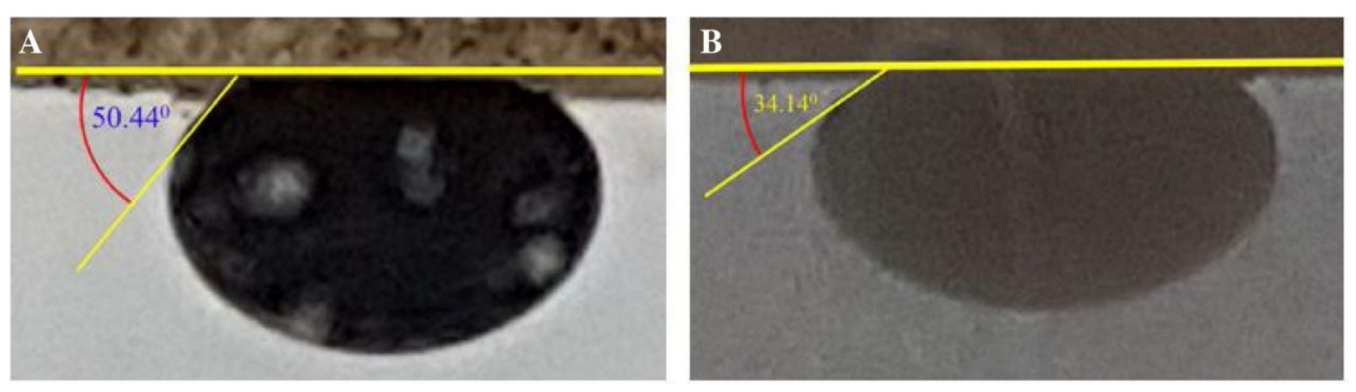

Figure 3. (A) Crude oil without nanoparticles (NPs). (B) Crude oil with ferrite NPs. From E. Esmaeilnezhad et al. [58] reprinted with permission.

For the analysis at ambient temperature and pressure, wettability associated with spontaneous forced and displacement processes can be determined by the Amott test, thereby determining the wettability index Iw; hence, the wettability index can be obtained using Equation (5) [4]:

$$
\mathrm{Iw}=\frac{V_{O 1}}{V_{O 1}-V_{O 2}}-\frac{V_{w 1}}{V_{w 1}+V_{w 2}}
$$

where $\mathrm{I}_{\mathrm{w}}$ represents wettability index, $V o$ and $V w$ represent oil volume and water volume respectively, while the subscripts " 1 " and " 2 " indicate spontaneous displacement process and forced displacement process, respectively. 
Table 1. Summary of the effects of Nanoparticle on Interfacial tension (IFT) and wettability alteration.

\begin{tabular}{|c|c|c|c|c|c|c|c|c|c|}
\hline \multirow{2}{*}{$\begin{array}{l}\text { Nanoparticles } \\
\text { (NPs) }\end{array}$} & \multirow[t]{2}{*}{ NPs Size } & \multicolumn{2}{|c|}{$\begin{array}{l}\text { Interfacial Tension } \\
\text { (IFT) }(\mathrm{mN} / \mathrm{m})\end{array}$} & \multicolumn{2}{|c|}{ Contact Angle $\left({ }^{\circ}\right)$} & \multirow[t]{2}{*}{ Porous Media } & \multirow[t]{2}{*}{ Fluids } & \multirow[t]{2}{*}{ Remark } & \multirow[t]{2}{*}{ Reference } \\
\hline & & Clean & With NP & Clean & With NP & & & & \\
\hline $\mathrm{ZnO}$ & 117.1 & 13.38 & 11.60 & 54 & 50 & Sandstone & Brine & Electromagnetic wave has influenced & [49] \\
\hline $\mathrm{Fe}_{2} \mathrm{O}_{3}$ & $20-35$ & 38.50 & 2.75 & 132 & 103 & Core plugs & Propanol & IFT is the dominant factor & [2] \\
\hline $\mathrm{Al}_{2} \mathrm{O}_{3}$ & 40 & 38.50 & 2.250 & 131 & 94 & Core plugs & Propanol & performance was satisfactory & [2] \\
\hline $\mathrm{SiO}_{2}$ & $10-30$ & 38.50 & 1.450 & 134 & 82 & Core plugs & Propanol & $\mathrm{SiO}_{2}$ was treated with silane & [2] \\
\hline $\mathrm{Al}_{2} \mathrm{O}_{3}$ & 17 & 19.20 & 12.80 & 131 & 28 & Quartz plate & Brine & IFT doesn't reflect in Enhanced Oil Recovery (EOR) & [51] \\
\hline $\mathrm{TiO}_{2}$ & 21 & 19.20 & - & 131 & 21 & Quartz plate & Brine & $\begin{array}{l}\text { The nanofluids were mixed with Polyvinylpyrrolidone } \\
\text { (PVP) polymer with significant results. }\end{array}$ & [51] \\
\hline $\mathrm{TiO}_{2}$ & $10-30$ & 21.10 & 17.50 & 57 & 46 & Limestone & Brine & $\begin{array}{l}\text { Lower adsorption on the surface of limestone } \\
\text { was observed. }\end{array}$ & [44] \\
\hline $\mathrm{Al}_{2} \mathrm{O}_{3}$ & 40 & 26.5 & 18 & 71 & 61 & Limestone & Brine & The adsorption capacity was law & [44] \\
\hline $\mathrm{SiO}_{2}$ & 20 & 26.5 & 17 & 26 & 18 & Limestone & Brine & $\begin{array}{l}\text { High adsorption on limestone rock was observed, } \\
\text { consequently, EOR was improved better. }\end{array}$ & [44] \\
\hline Ferrite NPs & $200-500$ & - & - & 50.44 & 34.14 & Sandstone & Brine & Fluids performed effectively & [58] \\
\hline $\mathrm{ZrO}_{2}$ & 40 & 8.46 & 1.85 & 70 & 60 & $\begin{array}{l}\text { Carbonate } \\
\text { doomite }\end{array}$ & $\begin{array}{l}\text { Cetyl Trimethyl } \\
\text { Ammonium } \\
\text { Bromide (CTAB) }\end{array}$ & Strong water wet was achieved & {$[56]$} \\
\hline $\mathrm{Al}_{2} \mathrm{O}_{3}$ & 20 & 8.46 & 1.65 & 70 & 52 & $\begin{array}{l}\text { Carbonate } \\
\text { dolomite }\end{array}$ & CTAB & Strong water wet was achieved & [56] \\
\hline $\mathrm{ZrO}_{2}$ & 40 & 9.88 & 2.78 & 92 & 84 & Carbonate & $\begin{array}{l}\text { sodium dodecyl } \\
\text { sulfate (SDS) }\end{array}$ & The NP performed satisfactory & {$[56]$} \\
\hline $\mathrm{Al}_{2} \mathrm{O}_{3}$ & 20 & 9.88 & 2.75 & 92 & 75 & Carbonate & SDS & $\begin{array}{l}\mathrm{Al}_{2} \mathrm{O}_{3} \text { shows better performance than } \mathrm{ZrO}_{2} \text { in all } \\
\text { dispersion }\end{array}$ & {$[56]$} \\
\hline $\mathrm{ZnO} / \mathrm{SiO}_{2}$ & - & 19.68 & 9.45 & 137 & 34 & Carbonate rock & Seawater & $\begin{array}{l}\text { Wettability was altered from strong oil-wet to strong } \\
\text { water-wet }\end{array}$ & [59] \\
\hline $\mathrm{Fe}_{2} \mathrm{O}_{4}$ & 50 & 30 & 17.3 & 145 & 90 & sandstone & Chitosan & Coating NPs is effective to EOR & [55] \\
\hline
\end{tabular}




\subsection{Disjoining Pressure}

The disjoining pressure is the situation in which additional oil can be revealed as a result of wedge-shaped film that was formed by the self-assembly of the nanofluids injected into the reservoir when the fluids are in contact with the oil phase. However, the appearance of the existing pressure was accredited to the fluids' injection pressure; as such, the NPs arrange themselves in a suitable form which leads to the creation of a wedge-shaped film that consequently boosts the mobility of the oil within the reservoir [4]. Figure 4 shows the NPs in a wedge-firm structure.

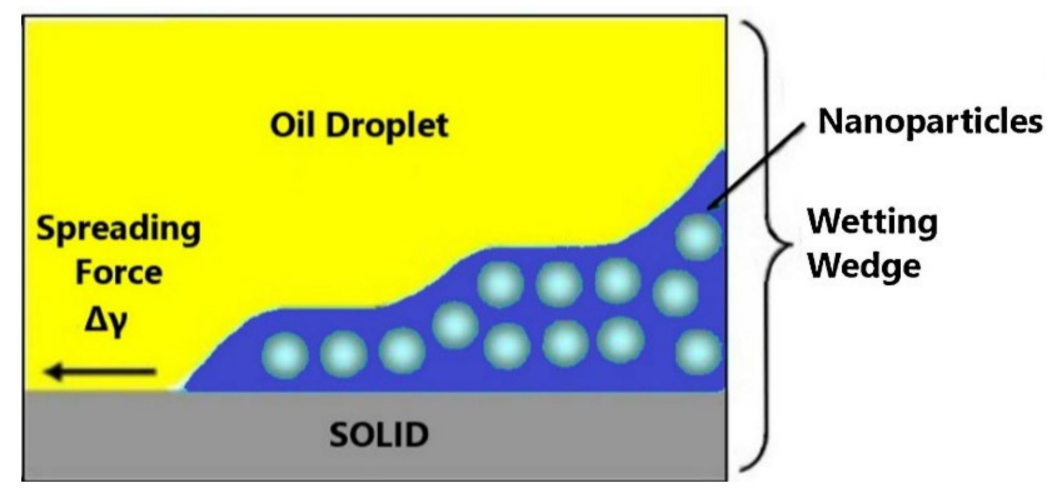

Figure 4. Nanoparticles in a wedge-film structure. Source: M. Adil, et al. [60] reprinted with permission.

\section{Influence of NPs' Surface Modification for Nanofluids Stability}

The stability of the dispersed nanoparticles is one of the critical issues that need to be addressed before the injection of the nanofluids in porous media. Ensuring the stability of the nanofluids is considered a prerequisite in optimizing the success of the nanoparticles during fluid injection. The factor that determines the stability of the suspended nanoparticles in fluids is attributed to the balance between gravitational forces, Van der Waals attractive forces, and electrical repulsive forces. If the gravitational and Van der Waals attractive forces between the particles are stronger than the electrical repulsive forces of the particles, it will result in the particles aggregating with each other and sedimentation will occur [61].

Coating surfactant or polymer on the surface of the NPs can bridge the existing gap between nanoparticles and that of the fluids [52]. Consequently, the particles will be prevented and inhibited from attracting each other or the nearby molecules, as a result of which stability can be accomplished [61]. The modifying surface of the particles has a limited application on EOR, although the concept was initiated in the early 1990s [62]. Surface modification of the NPs was reported to influence IFT reduction, and wettability changed $[52,59,62]$. This observable development is attributed to the incremental stage of the adsorption capacity of the particles at oil to water interface [52]. Moreover, polymer/surfactant coating on the surface of the NPs was found to promote nanofluid properties which include mobility, foams, emulsion, stability, and solubility of the fluids in a porous media $[59,61,63,64]$. Some experiments have shown that coating silicon dioxide nanoparticles with surfactant/polymer has revealed a productive outcome for EOR [59,61,65-67]. Furthermore, coating silica NP with $\mathrm{Al}_{2} \mathrm{O}_{3} \mathrm{NP}$ has made them appear with a higher surface area, which resulted in better recovery than with bare silica or alumina, as reported by Negin et al. [34]. It will be good if different nanoparticles will be coated by choosing a preferred NP or surfactant/polymer, which could hopefully show better results compared to mere polymer or surfactants or nanoparticles for EOR application. However, extra precautions need to be taken while selecting a polymer or surfactant by considering some environmental features like temperature, pressure, salinity, etc. Otherwise, the wrong selection of an appropriate polymer/surfactant can leads to a low recovery, and indeed it can be disadvantageous and detrimental to the reservoir, as 
they can block the reservoir rock pores. Moreover, NPs type, size, and concentrations also play a significant role in this regard.

\section{Metal Oxide NPs for EOR Application}

Recently, silica-based and metal-based NPs have tested brilliantly and offer promising means in recovering trapped oil from the reservoir, as shown by many researchers [51] Some metal oxide NPs exhibited special and exclusive advantage with regards to their physical and chemical properties which qualified them as the most widely used NPs for EOR in recent decades. The most commonly used metal oxide nanoparticles that were investigated for EOR are seven, namely: $\mathrm{ZnO}, \mathrm{TiO}_{2}, \mathrm{Al}_{2} \mathrm{O}_{3}, \mathrm{MgO}, \mathrm{ZrO}_{2}, \mathrm{CeO}_{2}$, and $\mathrm{Fe}_{2} \mathrm{O}_{3}[68]$.

Iron Oxide NPs $\left(\mathrm{Fe}_{2} \mathrm{O}_{3} / \mathrm{Fe}_{2} \mathrm{O}_{3}\right)$ were observed to perform reasonably towards EOR in a sandstone reservoir when brine and ethanol were used as a dispersion media [18]. Zinc Oxide NPs $(\mathrm{ZnO})$ performed satisfactorily based on the different experimental analyses which testified their numerous contributions to EOR $[46,49,69]$. Aluminum oxide $\left(\mathrm{Al}_{2} \mathrm{O}_{3}\right)$ NPs were observed to reduce the oil viscosity and oil-brine IFT [18]. Nickel Oxide NPs $\left(\mathrm{NiO} / \mathrm{Ni}_{2} \mathrm{O}_{3}\right)$ were dispersed in diesel and brine as a dispersion medium which improved wettability and viscosity [18]. Magnesium Oxide NPs $(\mathrm{MgO})$ were dispersed in distilled water and brine during core-flooding tests which showed low recovery due to permeability problems [18]. $\mathrm{ZrO}_{2} \mathrm{NPs}$ were observed to bring a change in the wettability of the core samples from oil-wet to water-wet [70]. Moreover, $\mathrm{ZrO}_{2}$ was reported to improve wettability alteration and IFT when combined with surfactant [71]. Titanium oxide $\left(\mathrm{TiO}_{2}\right)$ NPs influenced wettability change from oil-wet to water-wet virtually above other metal oxides NPs [72,73]. Copper oxide NPs $(\mathrm{CuO})$ were found to be good and eligible for oil improvement [72]. Tin Oxide NPs $\left(\mathrm{SnO}_{2}\right)$ have shown a reasonable outcome for EOR when dispersed in distilled water at room temperature using sandstone as a porous medium [18].

\section{Role of Electromagnetic Waves in EOR}

\subsection{Background on EM Waves Radiation}

EM Radiation refers to the photons of the electromagnetic field, which usually propagate through space, carrying electromagnetic radiant energy. Some examples are microwaves, ultraviolet, visible light, radio waves, $\mathrm{X}$-rays, etc. EM wave radiation usually propagates with oscillations of electric and magnetic fields. The position of an electromagnetic wave in the electromagnetic spectrum is largely attributed to either wavelength or frequency oscillation which eventually influences their interaction with matter. Electromagnetic waves are usually emitted by electrically charged particles which subsequently interact with other charged particles, resulting in exerting force on them. An EM wave carries energy from a respective source and conveys or transmits it to the matter that interacts with it, as illustrated in Figure 5.

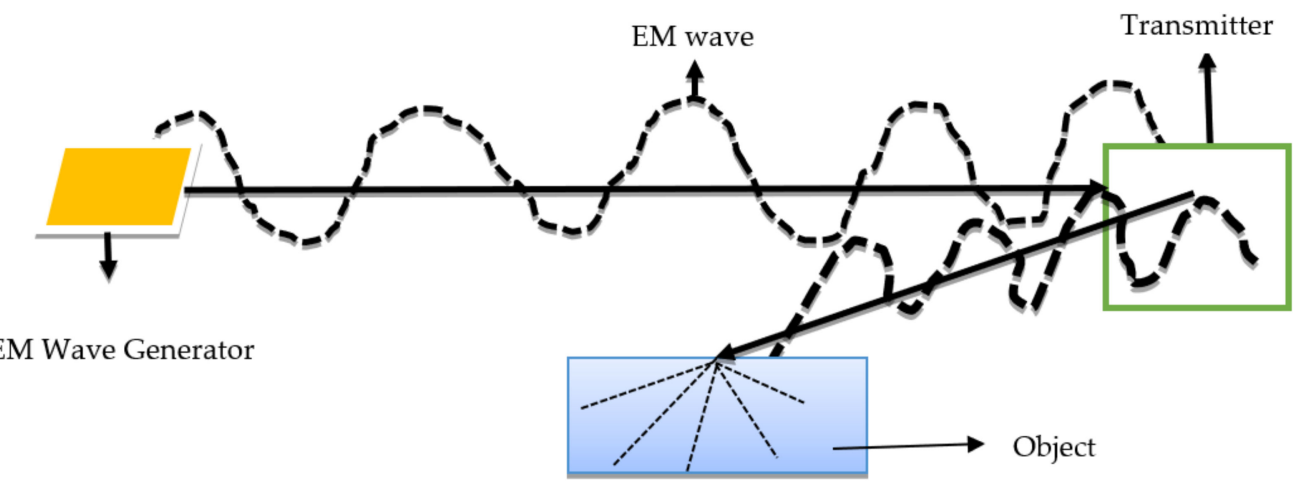

Figure 5. Electromagnetic waves propagation process. 


\subsection{Electromagnetic Heating for EOR}

Applying heat to the reservoir from EM sources is one of the most promising means through which the productivity of the oil can be enhanced. As late as the 1980s, an attempt was made in conducting the field application of EM heating to the reservoir which was unsuccessful due to some unavoidable circumstances. The investigation of the role played by the radiofrequency heating reservoir in the field application was conducted for the first time in 1992 at three different places, the first one in California and Utah situated in the USA, the second one at Bashkortostan and Tatarstan situated in Russia, and the last one at Alberta and Saskatchewan situated in Canada, and the outcome was satisfactory for EOR [74,75]. Electromagnetic heating is the thermal mechanism by which the reservoir is heated and the heat is disintegrated into the oil, which ultimately decreases the viscosity of the oil, resulting in increasing oil output. The transmission system from EM sources is usually found to be in the form of electrical energy coupled with some piece of metals or cables that can act as an interconnector that directly transmits heat to the reservoir. Moreover, this has made the situation possible in which electromagnetic heating the reservoir can be produced even at low frequency via radio and microwaves. It can perform at a lower frequency because power dissipates usually if high frequency is supplied from the EM source, as dictated by the expression $p=\sigma E^{2}$; whereas when electrical energy is applied under a low frequency (e.g., $50 \mathrm{~Hz}$ ), EM waves can produce resistive heating and eventually power will degenerate, as shown by expression $p=I^{2} \mathrm{R}$; however, heating can equally take place due to the support movement of the dipole of the molecules with EM waves [76]. The structure of the Electromagnetic heating reservoir for improving EOR is shown in Figure 6.

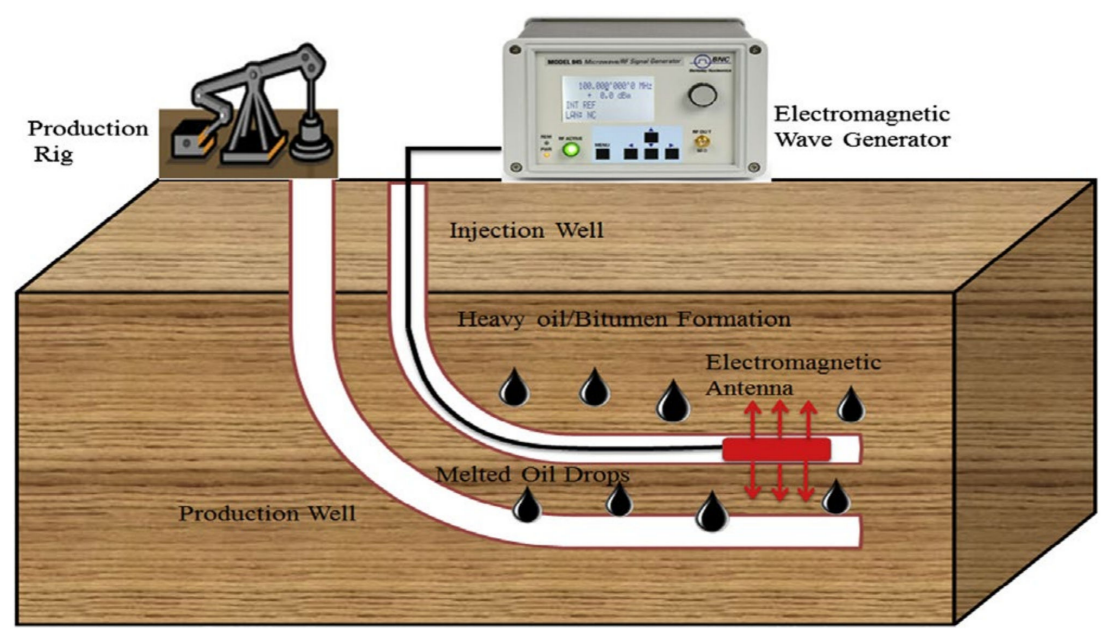

Figure 6. EM heating for Enhanced Oil Recovery (EOR). Source: Bera A. et al. [75] reprinted with permission.

\subsection{Influence of Nanofluids for EM-Assisted EOR}

Despite the significant aspect of employing chemical nanofluids in the reservoir being recently regarded as one of the most reliable processes accredited by modern science and technology, the injected nanofluids in the reservoir usually undergo agglomerations due to the harsh situation of the reservoir and consequently cause the segregation of the fluids from the oil/water interface, as a result of which the nanofluids suffer great trapping in rock pores of the reservoir, and hence the nanofluids transportation will be refrained [49]. Furthermore, the injected chemicals are highly disturbed by high temperature and the high pressure of reservoirs, which leads to some failure, fracture, and degradation of their performance [77]. The EM-assisted nanofluids will be a significant substitute to remedy this critical challenge because the energy disaffected from the EM sources can easily penetrate in the nanofluids, which leads to initiating some disturbances at the oil/water interface, and consequently, the movement of the oil can be facilitated. Significantly, utilizing this 
method can provide an enabling situation in which the properties of the injected fluids in the reservoir will be administered remotely by an external EM field in such a way that the smoothness mobility control of the fluids will be improved and subsequently the trapped oil can be released [78-80]. The EM-assisted nanoflooding for EOR is economically affordable and environmentally feasible compared to the other categories of EOR such as thermal, gas miscible, and chemical injection.

Experimental analysis using different NPs performed reasonably in this regard, such as $\mathrm{Fe}_{2} \mathrm{O}_{3}-\mathrm{Al}_{2} \mathrm{O}_{3}$ [77]. $\mathrm{CuO}, \mathrm{Fe}_{2} \mathrm{O}_{3}$, and $\mathrm{NiO}$ [81]. $\mathrm{ZnO}$ [49,54,82,83], $\mathrm{Fe}_{2} \mathrm{O}_{3}$ [84], etc., as will be discussed. This has indicated that this concept offers a significant approach in the laboratory scale analysis; however, it is yet to be effective in the field scale, which is one of the factors that necessities more research of the subject matter to find out the possible means for field scale applicability.

\section{Nanoparticles for EM-Assisted EOR}

Dielectric or magnetic properties of the metal oxide NPs were reported to have performed differently in EOR when irradiated with EM waves [69]. Magnetic or dielectric properties of the materials are the main properties that qualified material to become eligible to perform well and exclusively under the influence of EM wave radiation. Notably, their ability to absorb energy could lead to initiating some disturbances at the oil/water interface, as a result of which mobility of the oil can be improved [45]. Three basic requirements make particles become a good energy absorber under EM wave irradiation: namely, permittivity, permeability, and resistivity [85]. Some experimental results for EM assisted nanofluids flooding concerning the percentage of oil recovery is shown in Table 2.

Table 2. Summary of the experimental analysis of nanofluids flooding for EM-assisted enhanced oil recovery.

\begin{tabular}{|c|c|c|c|c|}
\hline NPs/Fluid Base & Oil Type & Rock Type & Recovery (\%) & Reference \\
\hline $\mathrm{ZnO} /$ brine & Heavy Crude oil & Glass parks & $14.8-26.2$ & [83] \\
\hline $\mathrm{Co}^{2+} \times \mathrm{Fe}^{2+}{ }_{1-\mathrm{X}} \mathrm{Fe}_{2}{ }^{3+} \mathrm{O} 4 /$ brine & Heavy oil & Sand parks & $11.63-17.44$ & {$[80]$} \\
\hline $\mathrm{Co}_{0 \cdot 4} \mathrm{Fe}_{0 \cdot 6} \mathrm{Fe}_{2} \mathrm{O}_{4} /$ brine & Miri Crude oil & Sand parks & 15.83 & [86] \\
\hline $\mathrm{Ni}_{1-\mathrm{x}} \mathrm{ZnxFe} \mathrm{O}_{3} /$ brine & Crude oil & Glass parks & 26.07 & [87] \\
\hline $\mathrm{ZnO} /$ brine & Crude oil & Sand park & $9.00-10.40$ & [49] \\
\hline $\mathrm{CoFe}_{2} \mathrm{O}_{4} /$ brine & Crude oil & Glass park & $8.70-31.58$ & [78] \\
\hline $\mathrm{Al}_{2} \mathrm{O}_{3} /$ brine & Crude oil & Sand park & $13.3-24.1$ & [18] \\
\hline $\mathrm{CuO}, \mathrm{NiO} /$ brine & Crude oil & Carbonate & $8.19 \& 7.59$ for $\mathrm{CuO} \& \mathrm{NiO}$, respectively & [81] \\
\hline $\mathrm{SiO}_{2}, \mathrm{Al}_{2} \mathrm{O}_{3}, \mathrm{Fe}_{2} \mathrm{O}_{3} /$ brine & Mineral oil & Sandstone & $8.99-20.42$ & {$[88]$} \\
\hline $\begin{array}{c}\mathrm{Fe}_{3} \mathrm{O}_{4} / \mathrm{SiO}_{2} \& \\
\mathrm{TiO}_{2} / \mathrm{SiO}_{2} / \text { brine }\end{array}$ & Crude oil & Sand park & $\begin{array}{c}24 \& 23 \text { for } \mathrm{Fe}_{3} \mathrm{O}_{4} / \mathrm{SiO}_{2} \& \mathrm{TiO}_{2} / \mathrm{SiO}_{2}, \\
\text { respectively }\end{array}$ & [89] \\
\hline $\mathrm{Fe}_{3} \mathrm{O}_{4} / /$ brine & Crude oil & Glass micromodel & 22 & [90] \\
\hline $\mathrm{Y}_{3} \mathrm{Fe}_{5} \mathrm{O}_{12} /$ brine & Heavy oil & Sand parks & 43.64 & [91] \\
\hline $\mathrm{Fe}_{3} \mathrm{O}_{4} / \mathrm{SiO}_{2} /$ brine & Crude oil & Glass micromodel & 13.2 & [92] \\
\hline $\mathrm{Fe}_{2} \mathrm{O}_{3}-\mathrm{Al}_{2} \mathrm{O}_{3}$ & Heavy oil & Silica beads & 24.25-30.00 & [77] \\
\hline $\mathrm{Al}_{2} \mathrm{O}_{3}, \mathrm{Fe}_{2} \mathrm{O}_{3} \& \mathrm{SiO}_{2}$ & Crude oil & Core plugs & 92.5, 88.6, and 95.3 for $\mathrm{Al}_{2} \mathrm{O}_{3}, \mathrm{Fe}_{2} \mathrm{O}_{3} \& \mathrm{SiO}_{2}$ & [2] \\
\hline
\end{tabular}

\subsection{Magnetic and Dielectric Nanofluids for EM-Assisted EOR}

Magnetic nanofluids deal with the colloidal suspensions of the magnetite NPs in a fluid-based material that consequently creates smart nanofluids that display overwhelmingly both magnetic and fluids properties [93]. The magnetic property of the NPs in the fluid-based material has prodigiously contributed towards the enhancement of the residual oil when activated by EM energy. This phenomenon was found to be consistent upon 
changing some parameters, such as IFT improvement, fluid viscosity, rock wettability alteration, fluid property modification, and smoothness mobility of the fluids in a porous medium [94]. Moreover, the influence of the magnetic properties over the alteration behavior of the fluids that could lead to oil stabilization is largely attributed to the size of the magnetic nanoparticles [94]. Magnetic and dielectric nanofluids played an important role in energy exposure, which in turn contributed enormously to EOR $[44,49,69,81,83,95]$.

Dielectric nanofluids, on the other hand, are a fluid-based material with two phases that comprise dielectric liquids as a medium for dispersion, and NPs as solid dispersion phases [96]. The dielectric nanofluids were found to be essential under the influence of EM waves. This is attributed to their dielectric loss, which renders the particles motivated when an external electric field is applied. Hence, the suspended particles in a liquid will eventually undergo polarization, which can result in improving the trapped oil by improving the mobility ratio of the fluids due to the electrorheological effect that leads to the incremental stage of the viscosity of the nanofluids [49]. Various dielectric nanofluids activated by EM wave irradiation have been studied in the last decade and showed promising results for enhanced oil recovery $[49,54,60,97,98]$.

\subsubsection{Ferro-Nanofluids}

For the first time, Kothari et al. (2010) [99] proposed the idea of employing smartnanofluid combined with the surfactant and conducted investigations on the EOR applications. The research focuses more on the effect of the rheological properties of the ferrofluids; the report verified that coating surfactant on the surface of the ferromagnetic NPs was significantly reported to have avoided agglomeration. Moreover, IFT was found to be reduced through continual addition of the surfactant, and according to them, this was found to be a worthy application regardless of the type of reservoir situation with regards to wettability, either oil wet or water wet. This idea has roused the interest of researchers to have a special look at hiring magnetic nanofluids for EOR.

Recently, Ali A.M. et al. (2020) [98] investigated the adsorption behavior of the Ferronanofluids of $\mathrm{Fe}_{2} \mathrm{O}_{3}$ and $\mathrm{Fe}_{3} \mathrm{O}_{4}$ on oil recovery. Studying the role of the adsorption capacity of the nanoparticles is significant because the transport mobility of the nanofluids in a reservoir is largely attributed to the adsorption of the particles on the surface of the rock. The study has shown that the ferrite nanofluids were instilled in reservoir sandstones, and the interfacial energy and adsorption of the ferrite fluids was determined using molecular dynamics simulation. The results showed that $\mathrm{Fe}_{3} \mathrm{O}_{4}$ ferrite nanofluids performed well and adequately at the liquid/fluids interface, which maximized IFT reduction.

\subsubsection{Cobalt Ferrite Nanofluids}

Yahya $\mathrm{N}$ et al. (2012) [78] studied the role of cobalt ferrite $\left(\mathrm{CoFe}_{2} \mathrm{O}_{4}\right)$ nanoparticles in EOR by conducting two experimental analyses. $\left(\mathrm{CoFe}_{2} \mathrm{O}_{4}\right)$ NPs with magnetic feeders were used in the first experiment to improve the magnetic field strength, whereas the ferrite nanofluids alone were used in the second experiment. During nanofluids injection, EM waves were introduced, which were observed to have exhibited a substantial outcome with regards to recovering the remaining oil in place (ROIP), in which $31.58 \%$ was recovered, whereas the analyzed nanofluids without EM were found to be $8.70 \%$. These ferrite NPs have not been extensively studied for EOR application despite the satisfactory outcome and more experiments are required via different nano flooding methods by using different reservoir rocks, and also to test whether the ability of the particles on IFT, wettability, and viscosity is significant. Similarly, Cobalt ferrite NPs of $\mathrm{Co}^{2+} \mathrm{x} \mathrm{Fe}{ }^{2+}{ }_{1-\mathrm{x}} \mathrm{Fe}_{2}{ }^{3+} \mathrm{O}_{4}$ and $\mathrm{Co}_{0 \cdot 4} \mathrm{Fe}_{0 \cdot 6} \mathrm{Fe}_{2} \mathrm{O}_{4}$ were reported to be significant in EOR under the EM field as reported by Suleiman et al. (2014) [80] and Suleiman et al. (2019) [86], respectively.

\subsubsection{Nickel-Zinc Ferrite Nanofluids $\left(\mathrm{Ni}_{1-\mathrm{x}} \mathrm{ZnxFe}_{2} \mathrm{O}_{3}\right)$}

Zaid H.M et al. (2014) [87] investigated the effect of the nickel to zinc ratio of magnetic NPs of Nickel-Zinc Ferrite $\left(\mathrm{Ni}_{1-\mathrm{x}} \mathrm{ZnxFe}_{2} \mathrm{O}_{3}\right)$ on oil recovery. The NPs were synthesized at 
various ratios by varying the value of $x$. A core flooding experiment was conducted. The ferrite nanofluids were injected into the compacted sand that was saturated with crude oil; subsequently, EM waves were introduced during the suspension; amongst the preferred magnetic nanofluids sample, the one with highest magnetization was when $x=0.5$ with the value of $52.6 \mathrm{emu} / \mathrm{g}$, detected using a Vibrating Sample Magnetometer (VSM); moreover, the same sample has also shown the highest recovery of $26.07 \%$.

\subsubsection{Lanthanum-Zinc Ferrite $\left(\mathrm{MnZnLa}_{\mathrm{x}} \mathrm{Fe}_{2-\mathrm{x}} \mathrm{O}_{4}\right)$}

Lee et al. (2019) [100] analyzed Mn-Zn ferrite NPs ( $\left.\mathrm{MnZnLa} \mathrm{Fe}_{2-\mathrm{x}} \mathrm{O}_{4}\right)$ substituted by Lanthanum $(\mathrm{La})$ at various values of $x(0.06,0.08,0.10)$. IFT and wettability of the studied ferrite nanofluids were analyzed. Sol-gel auto-combustion method was used for the synthesis of the materials, and the morphology, crystal structure, and magnetic property of the materials were analyzed via FESEM, XRD, and VSM, respectively. Subsequently, the ferrite nanofluids were prepared at three different weight percents $(0.01,0.03$, and 0.05$)$ dispersed in brine as the fluid base, and Sodium Dodecyl-benzene Sulfonate (SDBS) was added as a stabilizer. The outcome of the result has shown that the magnetic properties of the material were observed to be highest at $(\mathrm{La})$ composition when $x=0.08$. Furthermore, IFT reduction and wettability alteration was analyzed, and the ferrite nanofluids with $0.05 \mathrm{wt} \%$ have shown the best result for the analysis. It will be good if the core flooding experiment will be conducted to analyze what percentage of the oil can be recovered using this material.

\subsubsection{Yttrium Iron Garnet ( $\mathrm{YIG})\left(\mathrm{Y}_{3} \mathrm{Fe}_{5} \mathrm{O}_{12}\right)$}

Suleiman et al. (2016) [91] proposed the feasibility of employing Yttrium Iron Garnet (YIG) nanofluids for the EOR under EM wave exposure. The samples were synthesized and doubly annealed at $1200{ }^{\circ} \mathrm{C}$ (YIG 1200) and $1000{ }^{\circ} \mathrm{C}$ (YIG 1000) at the particle size of 49.69 and $37.69 \mathrm{~nm}$, respectively. YIG 1200 sample has shown the best property of permeability and magnetization via VSM analysis and therefore was selected for running EOR analysis. The core flooding test was conducted, and two pore volume of YIG nanofluids was injected into the porous media, and EM waves of $13.6 \mathrm{MHz}$ were exposed during magnetic nanofluids suspension. The result has shown that the remaining oil in place (ROIP) was observed to be $43.64 \%$. Significantly, it can be seen that $\mathrm{Y}_{3} \mathrm{Fe}_{5} \mathrm{O}_{12}$ is a suitable candidate for EOR. A few experiments were recently conducted by employing Yttrium Iron Garnet (YIG) nanofluids activated by EM waves and displayed a reasonable outcome by improving IFT, wettability, and viscosity [101-103].

\subsection{6. $\mathrm{Fe}_{2} \mathrm{O}_{3}-\mathrm{Al}_{2} \mathrm{O}_{3}$ Composite Nanofluids}

Suleimani et al. (2014) [77] investigated the effect of EM waves on the magnetization property of the composite nanofluids of $\mathrm{Fe}_{2} \mathrm{O}_{3}-\mathrm{Al}_{2} \mathrm{O}_{3}$ by $\mathrm{EM}$ irradiation at a frequency of $13.6 \mathrm{MHz}$. The research has reported that $\mathrm{Fe}_{2} \mathrm{O}_{3}-\mathrm{Al}_{2} \mathrm{O}_{3}$ nanocomposites material were dispersed in distilled water and subsequently injected via Silica beads as a porous medium at the rate of $1.0 \mathrm{~mL} / \mathrm{min}$ in $2.4 \mathrm{PV}$ with a size of $0.2 \mathrm{PV}$ for EOR analysis. Three nanofluids samples were labeled as S700, S800, and S900, during the suspension of the magnetic nanofluids, EM waves were introduced concurrently. The S900 nanofluids have shown the highest percentage of oil recovery at $30 \%$. The composite material of hematite and magnetic NPs is essential in terms of energy absorption during EM radiation exposure. Analyzing such composite material to investigate further on the IFT and wettability change under EM exposure will be significant. The different mechanisms of improving oil productivity are illustrated in Figure 7. 


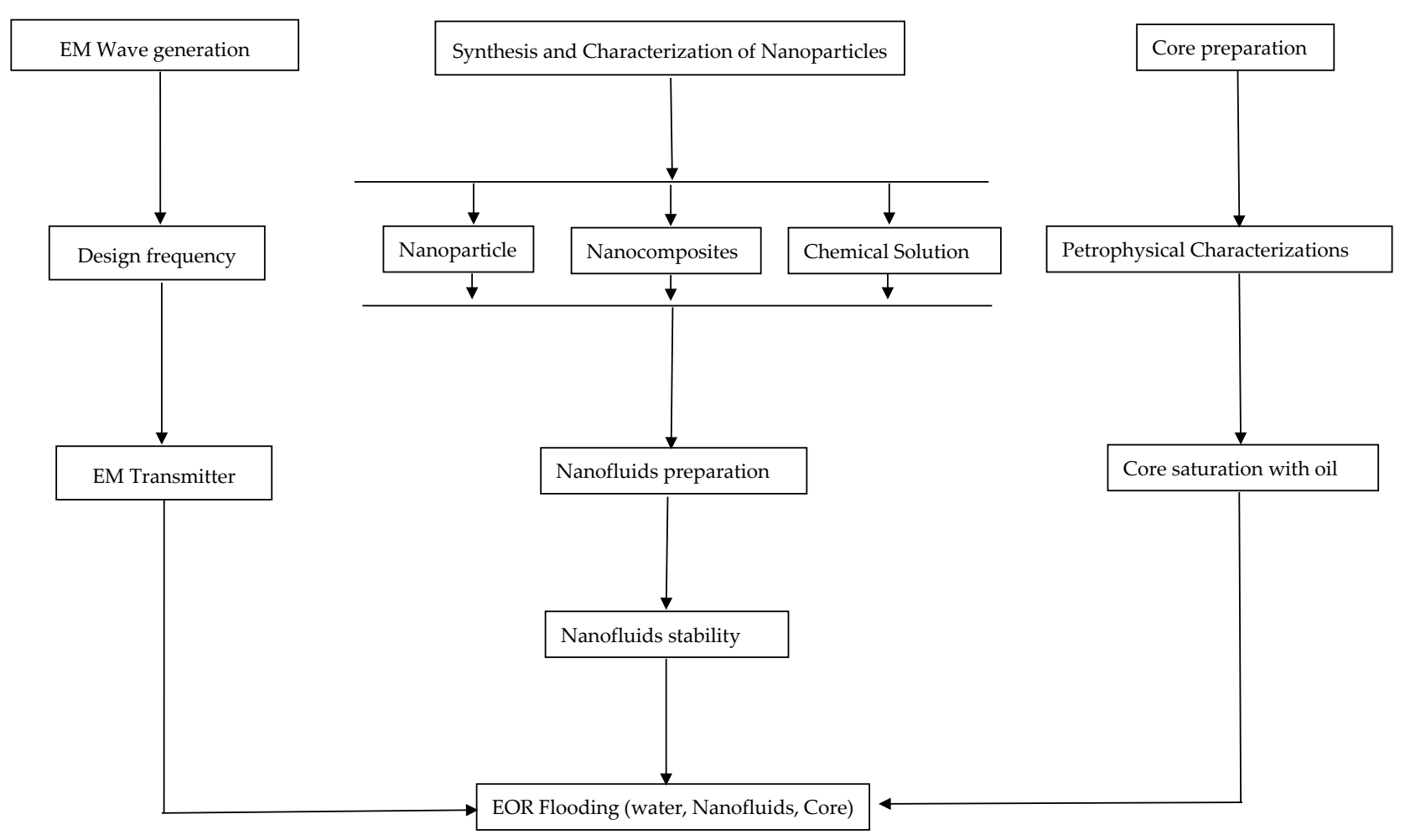

Figure 7. Flow chart of EOR experimental procedure.

\subsection{7. $\mathrm{Fe}_{3} \mathrm{O}_{4} / \mathrm{SiO}_{2}$ and $\mathrm{TiO}_{2} / \mathrm{SiO}_{2}$ Composites Nanofluids}

Kazamzadeh et al. (2018) [89] studied the effect of two metal oxide $/ \mathrm{SiO}_{2}$ nanocomposites materials $\left(\mathrm{Fe}_{3} \mathrm{O}_{4} / \mathrm{SiO}_{2}\right.$ and $\left.\mathrm{TiO}_{2} / \mathrm{SiO}_{2}\right)$ for EOR application at varying pressure. Carbonate sand pack flooding analysis was conducted at three different pressures of 14.7, 1500 , and $3500 \mathrm{psi}$. The outcome of the experiment revealed that the nanocomposite fluid performance was reliant on the pressure increment within the porous media. The result has shown that during $\mathrm{TiO}_{2}$ and $\mathrm{TiO}_{2} / \mathrm{SiO}_{2}$ nanofluids suspension, IFT reduction and wettability were found to be improved at ambient pressure, and the result has shown the recovery factor of 60 and $72 \%$ for $\mathrm{TiO}_{2}$ and $\mathrm{TiO}_{2} / \mathrm{SiO}_{2}$ nanofluids, respectively. Moreover, at high pressure (3500 psi), $\mathrm{Fe}_{3} \mathrm{O}_{4}$ and $\mathrm{Fe}_{3} \mathrm{O}_{4} / \mathrm{SiO}_{2}$ composites nanofluids were observed to have exhibited a higher recovery factor of 56 and $69 \%$ for $\mathrm{Fe}_{3} \mathrm{O}_{4}$ and $\mathrm{Fe}_{3} \mathrm{O}_{4} / \mathrm{SiO}_{2}$ nanofluids, respectively. Conclusively, the studied composite nanofluids at pressures of 3500 and 1500 psi improved the oil recovery by 24 and $23 \%$ for $\mathrm{Fe}_{3} \mathrm{O}_{4} / \mathrm{SiO}_{2}$ and $\mathrm{TiO}_{2} / \mathrm{SiO}_{2}$, respectively.

Furthermore, Kazamzadeh et al. (2019) [92] investigated the performance of four different fluids for EOR application; the studied nanofluids include $\mathrm{Fe}_{3} \mathrm{O}_{4} / \mathrm{SiO}_{2}, \mathrm{Fe}_{3} \mathrm{O}_{4}$, $\mathrm{SiO}_{2}$, and seawater. These four fluids were analyzed individually in the designed glass micromodel. The result has shown that $\mathrm{Fe}_{3} \mathrm{O}_{4} / \mathrm{SiO}_{2}$ nanofluids were reported to have performed well and been effective with regards to EOR compared to other fluids studied. The dominant mechanism for $\mathrm{Fe}_{3} \mathrm{O}_{4} / \mathrm{SiO}_{2}$ nanofluids was the wettability alteration in a porous medium. Moreover, the emulsion stability was also observed in the first place during $\mathrm{Fe}_{3} \mathrm{O}_{4} / \mathrm{SiO}_{2}$ nanofluids injection till the end of the suspension; consequently, the viscosity of the displacing fluids was increased. However, wettability and IFT were equally improved by nanofluids of $\mathrm{SiO}_{2}$ and seawater, but the overall leading nanofluids for oil recovery were $\mathrm{Fe}_{3} \mathrm{O}_{4} / \mathrm{SiO}_{2}$, which appeared to be in the order of $\mathrm{Fe}_{3} \mathrm{O}_{4} / \mathrm{SiO}_{2}>$ seawater > $\mathrm{Fe}_{3} \mathrm{O}_{4}>\mathrm{SiO}_{2}$.

\subsubsection{Coating $\mathrm{Fe}_{3} \mathrm{O}_{4} \mathrm{NPs}$}

Recently, Izadi et al. (2019) [104] investigated the influence of polymer-citrate-coated $\mathrm{Fe}_{3} \mathrm{O}_{4} \mathrm{NPs}$ using reservoir temperatures and pressure at high salinity for EOR. The salinity 
was up to $256,000 \mathrm{ppm}$ at a temperature of $85^{\circ} \mathrm{C}$ and pressure of $2700 \mathrm{psi}$; moreover, the experiment was conducted by using carbonate rocks and sand-pack as a porous medium during nanofluids suspension. The result has shown some level of deficiency while using citrate-coated $\mathrm{Fe}_{3} \mathrm{O}_{4}$ NPs at room temperatures compared to polymer-citrate-coated $\mathrm{Fe}_{3} \mathrm{O}_{4}$ with regards to the stability of the particles. Furthermore, the result has shown that polymercitrate-coated $\mathrm{Fe}_{3} \mathrm{O}_{4}$ NPs were found to have influenced IFT reduction and wettability alteration. Subsequently, nanofluid flooding was conducted and displayed a reasonable outcome for EOR. Recently, Divandari et al. (2019) [90] studied $\mathrm{Fe}_{3} \mathrm{O}_{4}$ coated with citric acid and a very good result was reported for EOR improvements.

\subsection{9. $\mathrm{ZnO}$ and $\mathrm{Al}_{2} \mathrm{O}_{3}$ Nanofluids}

Zinc Oxide $(\mathrm{ZnO})$ is one of the NPs that has contributed immensely to different fields of study, such as food items, semiconductors, rubber material, photocatalysis, and ceramics [43]. Aluminum oxide $\left(\mathrm{Al}_{2} \mathrm{O}_{3}\right)$, on the other hand, is also a metal oxide NP that can be invented using different processes, such as modified plasma arc [105], mechanochemical methods [106], or flame spray pyrolysis [107]. Recent experimental analysis testified that zinc oxide and aluminum oxide have contributed immensely to EOR. M. Adil et al. (2017) [97] investigated the electrorheological effect of the nanofluids of $\mathrm{ZnO}$ and $\mathrm{Al}_{2} \mathrm{O}_{3}$ calcined at a various temperature. Nanofluids were prepared at the weight percentage of $0.1,0.05$, and 0.01 using tap water, salt water, and air as dispersion media that were propagated by a solenoid-based electromagnetic (EM) transmitter. The result has shown that the particles of the materials have revealed a very strong attraction at a high electric field, as expected. Moreover, the fluid's viscosity was reported to have increased more preferably in tap water followed by saltwater when the electric field was applied. However, the decrease of the viscosity of the nanofluids was observed for saltwater within the range of $4-10 \%$ and $17-24 \%$ for $\mathrm{ZnO}$ and $\mathrm{Al}_{2} \mathrm{O}_{3}$, respectively. This was attributed to the conductive effect of the tap water, and also considering the fact that low salinity of tap water has made them have a low attenuation of energy. Moreover, while using air as propagation medium, the performance concerning viscosity was reasonable only in the presence of an EM wave due to the lower conductivity of the air.

Recently, M. Adil, et al. (2020) [60] studied the characteristics of dielectric nanofluids of $\mathrm{ZnO}$ and $\mathrm{Al}_{2} \mathrm{O}_{3}$ by measuring IFT and wettability under EM waves irradiation. The dielectric nanofluids dispersant for the experiment were brine and SDBS, the size of the particles was within the range of 43.4-47.3 and 25-94.3 nm for $\mathrm{ZnO}$ and $\mathrm{Al}_{2} \mathrm{O}_{3} \mathrm{NPs}$, respectively. The study has shown that the energy applied via EM field enhanced NPs with a high level of absorption has created some disruption by distorting the shape of the oil droplet that consequently make some reduction in IFT from 13.38 to 11.60 and 13.35 to 8.10 $\mathrm{mN} / \mathrm{m}$ for $\mathrm{ZnO}$ and $\mathrm{Al}_{2} \mathrm{O}_{3} \mathrm{NPs}$ respectively as shown in Figures 8 and 9. However, the IFT reduction of the oil/nanofluids was attributed to the dielectric loss of nanoparticles, which was reported to have provided an enabling situation in which the rotational polarization created a high level of agitation of the particles. The contact angle was reduced from $42.70^{\circ}$ to $36.01^{\circ}$ for $\mathrm{Al}_{2} \mathrm{O}_{3} \mathrm{NPs}$; this was also attributed to the mobility of the polarized dipoles and free charges that were activated by the EM field.

Adil et al. (2018) [49] investigated the effect of zinc oxide NPs for EOR application at a particle size of 55.7 and $117.1 \mathrm{~nm}$ under the irradiation of EM waves at high temperatures $\left(95^{\circ} \mathrm{C}\right)$. Viscosity, IFT, and wettability were measured in the first place. Hence, the nanoflooding system was conducted using sand packs as a reservoir replicator. Zinc oxide nanofluid flooding and surfactant flooding (SDBS) were carried out accordingly; the results have shown that the particle sizes of ZnO NPs were reported to have improved IFT and wettability in such a way that the recovery increases with an increase in the particle size of the material, as similarly reported by Lee et al. (2016) [46]. Moreover, nano flooding of $\mathrm{ZnO}$ with high particle sizes of $117.1 \mathrm{~nm}$ labelled as ZnO@800 NF was treated as EM-assisted nano flooding, which displayed a higher recovery in comparison to the one with the smaller particle size of 55.7 nm, labeled Zn@500 NF. This was attributed to 
the high level of disturbance between the fluids interface because particle sizes undergo polarization which subsequently caused the IFT reduction from 13.38 to $11.60 \mathrm{mN} / \mathrm{m}$ for ZnO@800 NF compared to 10.86 to 10.02 mN/m for Zn@500 NF. Hence, the highest oil recovery from the experiment was observed to be $9 \pm 10.4 \%$ of Original Oil in Place (OOIP) during EM-assisted nano flooding analysis, whereas $8.5 \pm 10.2 \%$ of OOIP was observed during surfactant flooding. The work has recommended promising approaches in which $\mathrm{ZnO}$ nanofluids give a rise in recovering more oil by displacing the trapped oil at reservoir temperature. Recently, some experiments were also conducted using $\mathrm{ZnO}$ nanofluids under EM exposure at reservoir temperature with a reasonable outcome for EOR, as reported by Lee et al. (2019) [54] and Zaid H.M et al. (2018) [82].

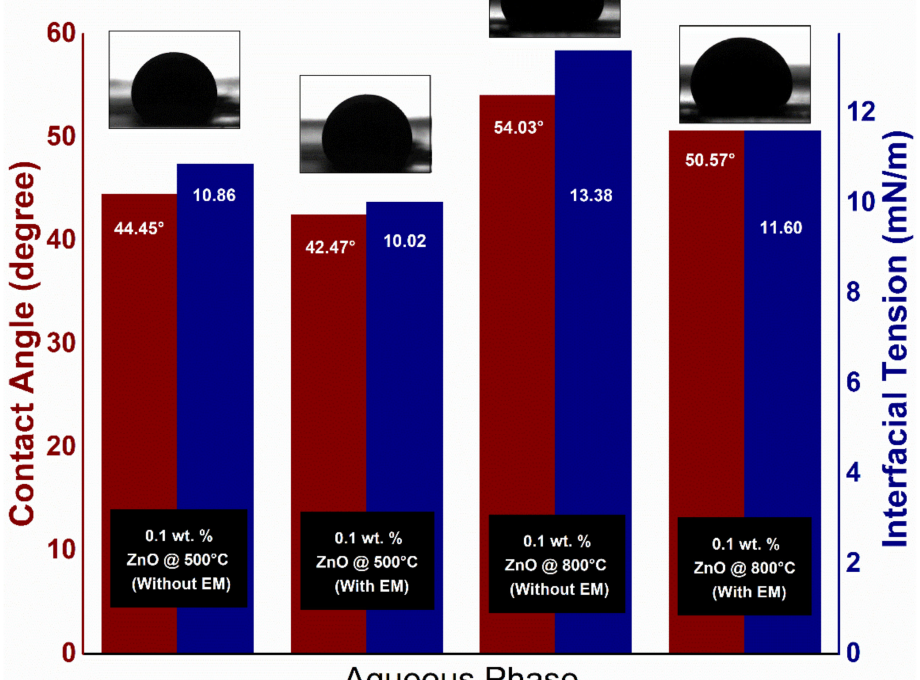

Figure 8. IFT and contact angle of the oil droplet using $\mathrm{ZnO}$ nanofluids under the EM field. Source: M. Adil, et al. [60] reprinted with permission.

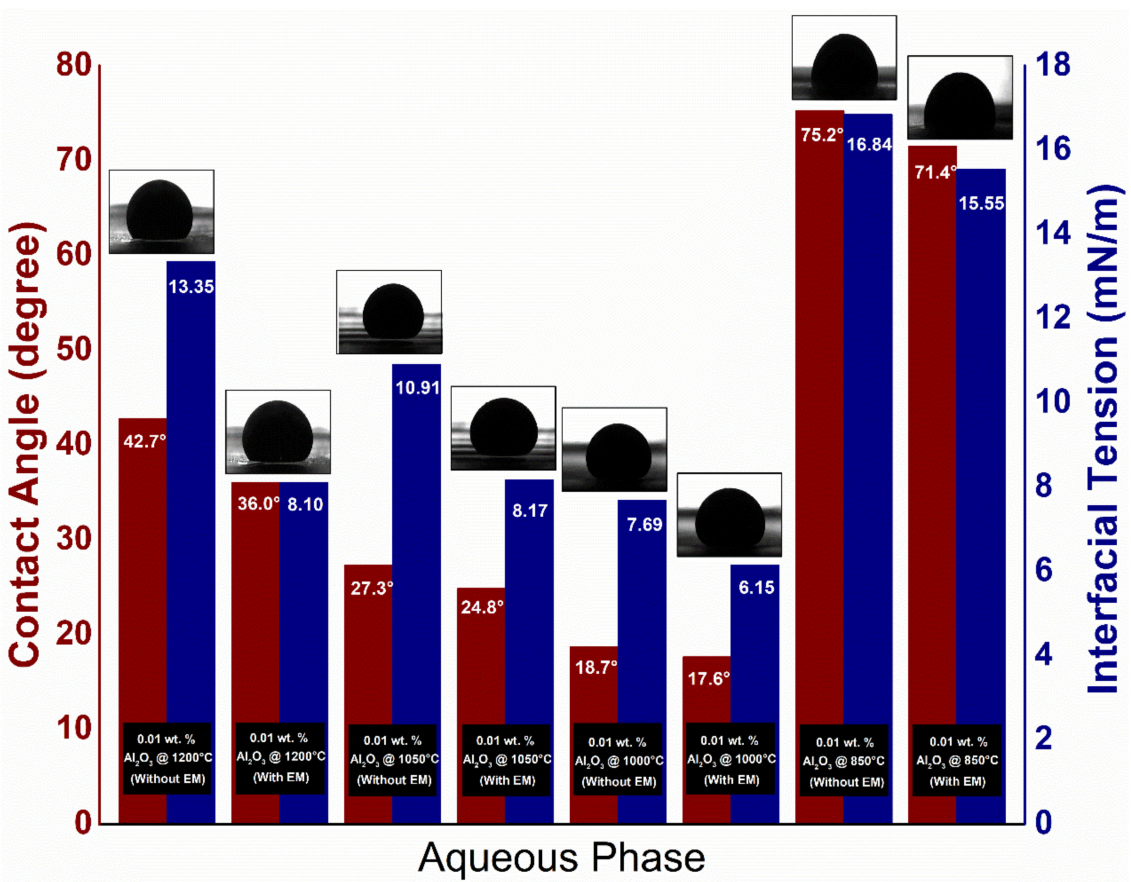

Figure 9. IFT and contact angle of the oil droplet using $\mathrm{Al}_{2} \mathrm{O}_{3}$ nanofluids under the EM field. Source: M. Adil, et al. [60] reprinted with permission. 
H. Ali et al. (2020) [108] studied the EM wave absorption capacity of NPs using sandstone as a porous medium injected and saturated by three prepared nanofluids of brine, Zinc Oxide ( $\mathrm{ZnO})$, and Bismuth ferrite $\mathrm{BiFeO}_{3}(\mathrm{BFO})$. The facile sol-gel method was used for the synthesis of the NPs, and nanofluids were prepared before the dispersion analysis. Brine, and nanofluids of $\mathrm{ZnO}$ and $\mathrm{BiFeO}_{3}$ were saturated in the prepared sandstone for two days. Vector network analyzer was used for the measurement of the magnetic and dielectric properties of the materials. The result has verified that $\mathrm{BiFeO}_{3}$ nanofluids were observed to have shown the best magnetic and dielectric properties. Hence, $\mathrm{BiFeO}_{3}$ displayed high absorption capacity under electromagnetic irradiation which qualified them as the most suitable nanofluids for the EOR test.

\section{EM-Assisted Oil Recovery Mechanisms}

\subsection{Electrorheological Effect}

The phenomenon that deals with the properties associated with the flow of matter (i.e., rheology) under the influence of the electric field is termed the electrorheological effect [109]. Therefore, the nanoparticles are to be dispersed in a fluid that consequently undergoes polarization, reorientation, and alteration in the viscosity when an electric field is applied [110]. The polarization of the particles can be observed in which the molecules arrange themselves toward the direction of the electric field which is attributed to the dielectric constant, whereas the particle's reorientation, on the other hand, depends upon the dielectric loss measurement [58]. Significantly, the presence of an electric field in that formation of fluids will cause an alteration of the particles in the fluids within which the mobility ratio will be improved.

\subsection{Oil Droplet Deformation}

Oil droplet deformation is one of the important mechanisms that show the effectiveness of the EOR by improving the fluid mobility within reservoir rock through surfactant or water flooding [111]. The deformation of the oil shape was observed to be well improved in the presence of the external field [112]. It makes it more productive if the nanoparticles will be employed in the presence of an electric field in such a way that more disturbances will be observed within the fluids' interface and the oil shape will be deformed tremendously as a result of which more oil can be released (see Figure 10) [49]. Previous research on the relevant literature of employing EM-assisted nanofluids for EOR is summarized in Table 3.

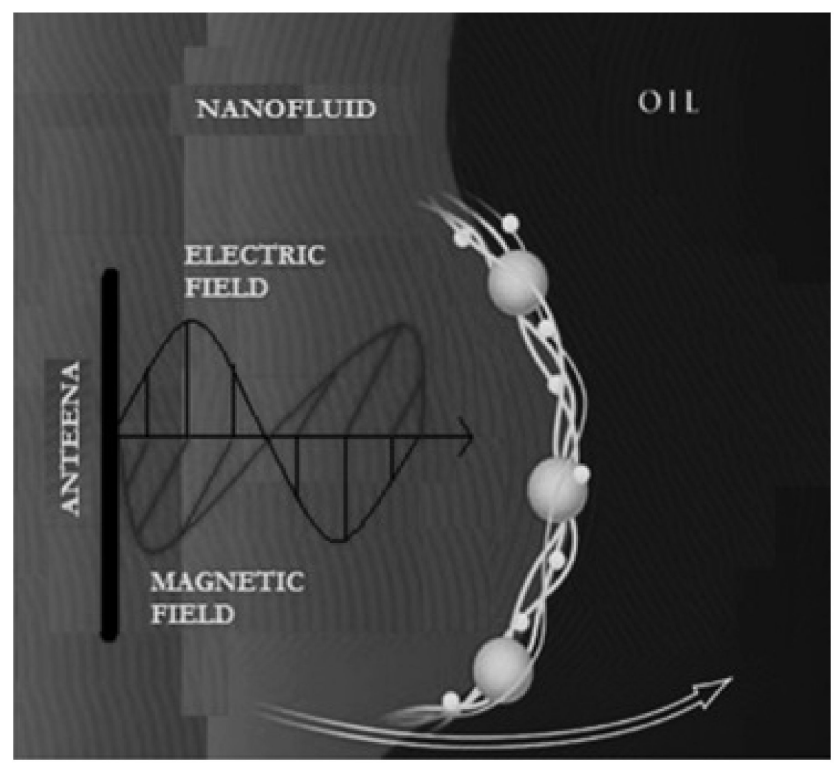

Figure 10. Disturbance at oil/water interface when EM waves were applied in the presence of dielectric nanofluids. Source: M. Adil, et al. [60] reprinted with permission. 
Table 3. Overview of the experimental analysis for the magnetic and dielectric nanofluids for EM-assisted enhanced oil recovery.

\begin{tabular}{|c|c|c|c|c|c|}
\hline Nanoparticles & Scope of Study & EM Freq. (MHz) & Outcome & Remark & Ref. \\
\hline $\mathrm{ZnO}$ & $\begin{array}{l}\text { Determination of fluid } \\
\text { viscosity, IFT, contact angle \& } \\
\text { Nano flooding test. }\end{array}$ & - & $\begin{array}{l}\text { Zinc oxide Nano flooding performed reasonably } \\
\text { to EOR under the irradiation of EM waves at a } \\
\text { reservoir temperature }\left(95^{\circ} \mathrm{C}\right) \text {. }\end{array}$ & $\begin{array}{l}\text { Most of the experiments were conducted under } \\
\text { ambient temp. It will be essential to have more } \\
\text { studies under reservoir temp. }\end{array}$ & [49] \\
\hline $\mathrm{ZnO}$ & $\begin{array}{l}\text { Electrorheological effect of } \\
\text { ZnO NPs activated by the } \\
\text { electric field. }\end{array}$ & $167 \& 18.8$ & $\begin{array}{l}\text { The viscosity increase was highly dependent on } \\
\text { the increment of the applied electric field. }\end{array}$ & $\begin{array}{l}\text { Varying the particle size of the material might } \\
\text { influence changes in the fluid viscosity. }\end{array}$ & [82] \\
\hline $\mathrm{ZnO}$ & $\begin{array}{l}\text { Nano flooding was irradiated } \\
\text { with EM waves }\end{array}$ & 0.001 & $\begin{array}{l}26.2 \% \text { of the oil was recovered during EM } \\
\text { exposure to the fluids, whereas } 14.8 \% \text { was } \\
\text { recovered in the absence of EM waves. }\end{array}$ & $\begin{array}{l}\text { The EM wave facilitates } \mathrm{ZnO} \text { nanofluids; } \\
\text { however, other parameters that influenced the } \\
\text { EOR mechanism have not been studied. }\end{array}$ & [83] \\
\hline $\mathrm{ZnO}$ & Viscosity \& IFT test & 18.8 & $\begin{array}{l}\text { Viscosity and interfacial tension (IFT) were } \\
\text { found to have increased with an increase in } \\
\text { particle sizes }\end{array}$ & $\begin{array}{l}\text { The crystal size of the material has performed } \\
\text { effectively by annealing at different temp. }\end{array}$ & [46] \\
\hline $\mathrm{ZnO}$ & $\begin{array}{l}\text { Fluids stability and } \\
\text { rheological effect using } \\
\text { surfactants }\end{array}$ & - & $\begin{array}{l}\text { Increasing the surfactants led to the increment } \\
\text { in the stability of the dispersed nanoparticles. }\end{array}$ & $\begin{array}{l}\text { The presence of EM waves in the fluids has } \\
\text { shown an increment to the viscosity. }\end{array}$ & [113] \\
\hline $\mathrm{ZnO}$ & $\begin{array}{l}\text { IFT, viscosity and wettability } \\
\text { under EM waves }\end{array}$ & - & $\begin{array}{l}\text { The presence of EM waves has improved the } \\
\text { IFT reduction, and increased fluid viscosity and } \\
\text { wettability alteration. }\end{array}$ & $\begin{array}{l}\text { The optimum frequency to be applied during } \\
\text { EM wave irradiation is a matter of concern. }\end{array}$ & [54] \\
\hline $\mathrm{ZnO}$ and $\mathrm{Al}_{2} \mathrm{O}_{3}$ & $\begin{array}{l}\text { IFT and wettability under EM } \\
\text { wave irradiation. }\end{array}$ & - & $\begin{array}{l}\text { IFT was reduced from } 13.35 \text { to } 8.10 \mathrm{Mn} / \mathrm{m} \text { for } \\
\mathrm{Al}_{2} \mathrm{O}_{3} \mathrm{NPs} \text {, so the contact angle was equally } \\
\text { reduced from } 42.76^{\circ} \text { to } 36.01^{\circ} .\end{array}$ & $\begin{array}{l}\text { The nanofluids of } \mathrm{Al}_{2} \mathrm{O}_{3} \text { performed better than } \\
\text { those of } \mathrm{ZnO} \text { nanofluids. }\end{array}$ & [60] \\
\hline $\mathrm{ZnO}$ and $\mathrm{Al}_{2} \mathrm{O}_{3}$ & IFT & - & $\begin{array}{c}\text { Crystal sizes of the materials have influenced } \\
\text { EOR. }\end{array}$ & $\begin{array}{l}\text { It will be essential to investigate the effect of } \\
\text { crystal sizes of the materials on viscosity and } \\
\text { wettability. }\end{array}$ & [114] \\
\hline $\mathrm{ZnO}$ and $\mathrm{Al}_{2} \mathrm{O}_{3}$ & Electrorheology & 167 & $\begin{array}{l}\text { The particles of the dielectric NPs have revealed } \\
\text { a very strong attraction at the high electric field. }\end{array}$ & $\begin{array}{c}\text { Tap water, salt water, and air performed } \\
\text { effectively as a dispersion media for conveying } \\
\text { NPs to the reservoir when EM waves were } \\
\text { applied. }\end{array}$ & [96] \\
\hline $\mathrm{ZnO}$ and $\mathrm{BiFeO}_{3}$ & $\begin{array}{l}\text { Adsorption capacity of the } \\
\text { material. }\end{array}$ & $8500-12,500$ & $\begin{array}{c}\mathrm{BiFeO}_{3} \text { nanofluids were observed to be superior } \\
\text { in the adsorption capacity, dielectric, and } \\
\text { magnetic properties. }\end{array}$ & $\begin{array}{l}\mathrm{BiFeO}_{3} \text { is a very good agent for EOR; hence, } \\
\text { more analysis needs to be done by running core } \\
\text { flooding analysis, IF, and wettability test. }\end{array}$ & [108] \\
\hline
\end{tabular}


Table 3. Cont.

\begin{tabular}{|c|c|c|c|c|c|}
\hline Nanoparticles & Scope of Study & EM Freq. (MHz) & Outcome & Remark & Ref. \\
\hline $\mathrm{ZnO}$ and $\mathrm{Al}_{2} \mathrm{O}_{3}$ & Electrorheology and viscosity & 167 & $\begin{array}{c}\text { The viscosity of the nanofluids for both } \mathrm{ZnO} \\
\text { and } \mathrm{Al}_{2} \mathrm{O}_{3} \text { has improved when exposed to EM } \\
\text { waves }\end{array}$ & $\begin{array}{l}\text { The EM transmitter used in the analysis was } \\
\text { observed to have propagated reasonably at an } \\
\text { optimum voltage of } 1.5 \mathrm{v} \text {. }\end{array}$ & [69] \\
\hline $\mathrm{ZnO}$ and $\mathrm{Al}_{2} \mathrm{O}_{3}$ & $\begin{array}{l}\text { Fluids Viscosity, wettability } \\
\text { test, and nano flooding }\end{array}$ & 50 & $\begin{array}{l}\text { When the EM wave was exposed to the } \\
\text { dielectric nanofluids, more oil was recovered. }\end{array}$ & $\begin{array}{c}\text { Nanofluids of } \mathrm{ZnO} \text { have shown lower IFT } \\
\text { compared to that of } \mathrm{Al}_{2} \mathrm{O}_{3} \text { nanofluids }\end{array}$ & [45] \\
\hline$\left(\mathrm{CoFe}_{2} \mathrm{O}_{4}\right)$ & Nanofluids flooding analysis & - & $\begin{array}{l}\text { When the EM wave was exposed to the } \\
\text { magnetic cobalt ferrite nanofluids, more oil was } \\
\text { recovered. }\end{array}$ & $\begin{array}{c}\text { High energy absorbance of the cobalt ferrite } \\
\text { NPs leads to reduced oil viscosity, which in turn } \\
\text { improves EOR. }\end{array}$ & [78] \\
\hline $\begin{array}{l}\mathrm{Co}^{2+} \mathrm{xFe}^{2+}{ }^{1-\mathrm{x}} \\
\mathrm{Fe}_{2}{ }^{3+} \mathrm{O}_{4}\end{array}$ & Core flooding test & 78 & $\begin{array}{c}\text { The total recovery efficiency was observed to be } \\
17.44 \% \text { with EM and } 11.63 \% \text { without EM. }\end{array}$ & $\begin{array}{l}\text { The mechanisms that influence the efficiency of } \\
\text { the EOR have not been studied. }\end{array}$ & [80] \\
\hline $\mathrm{Co}_{0 \cdot 4} \mathrm{Fe}_{0 \cdot 6} \mathrm{Fe}_{2} \mathrm{O}_{4}$ & Sand pack flooding & - & $\begin{array}{l}15.83 \% \text { of the residual oil was recovered in the } \\
\text { presence of a magnetic field, whereas } 7.20 \% \text { was } \\
\text { recovered in the absence of a magnetic field. }\end{array}$ & $\begin{array}{l}\text { The presence of the magnetic field leads to the } \\
\text { generation of some resistance to the flowing } \\
\text { fluids that consequently increased the viscosity } \\
\text { of the ferrofluids. }\end{array}$ & [86] \\
\hline $\mathrm{Ni}_{1-\mathrm{x}} \mathrm{Zn}_{\mathrm{x}} \mathrm{Fe}_{2} \mathrm{O}_{3}$ & Core flooding test & - & $\begin{array}{l}26 \% \text { was observed to be the highest recovery for } \\
\text { EOR at the value of } x=0.5\end{array}$ & $\begin{array}{l}\text { More core flooding tests need to be done by } \\
\text { varying injection fluids and reservoir rocks. }\end{array}$ & [87] \\
\hline $\begin{array}{c}\mathrm{Y}_{3} \mathrm{Fe}_{5} \mathrm{O}_{12} \\
\mathrm{Y}=\underset{\text { garnet }}{\mathrm{Yttrium} \text { iron }}\end{array}$ & Core flooding & 13.6 & $\begin{array}{c}\mathrm{Y}_{3} \mathrm{Fe}_{5} \mathrm{O}_{12} \text { nanofluids flooding recovered } 43.64 \% \\
\text { when irradiated with EM waves. }\end{array}$ & $\begin{array}{l}\text { The NPs annealed at a high temp. have shown } \\
\text { the best recovery. }\end{array}$ & [91] \\
\hline $\begin{array}{c}\mathrm{Y}_{2 \cdot 8} \mathrm{R}_{0 \cdot 2} \mathrm{Fe}_{5} \mathrm{O}_{12} \\
(\mathrm{R}=\mathrm{La}, \mathrm{Nd}, \mathrm{Sm}) \\
\mathrm{La}=\text { Lanthanum } \\
\mathrm{Nd}=\text { Neodymium } \\
\mathrm{Sm}=\text { Samarium }\end{array}$ & $\begin{array}{l}\text { IFT, viscosity and wettability } \\
\text { under EM waves }\end{array}$ & 100 & $\begin{array}{l}\text { Wettability was improved in EM exposure to the } \\
\text { nanofluids, contrary to IFT and viscosity }\end{array}$ & $\begin{array}{l}\text { Employing material with high-temperature } \\
\text { stability will be significant during the } \\
\text { prospective analysis. }\end{array}$ & [101] \\
\hline $\mathrm{Y}_{3} \mathrm{Fe}_{5} \mathrm{O}_{12}$ & $\begin{array}{l}\text { IFT, and viscosity under EM } \\
\text { waves }\end{array}$ & - & $\begin{array}{l}\text { IFT reduction and viscosity were improved } \\
\text { more when EM waves were applied. }\end{array}$ & $\begin{array}{c}\mathrm{Y}_{3} \mathrm{Fe}_{5} \mathrm{O}_{12} \text { is a suitable NP that has performed } \\
\text { reasonably for EOR. }\end{array}$ & [102] \\
\hline $\begin{array}{c}\mathrm{Y}_{3-\mathrm{x}} \mathrm{Nd}_{\mathrm{x}} \mathrm{Fe}_{5} \mathrm{O}_{12} \\
\mathrm{Nd}=\text { Neodymium }\end{array}$ & $\begin{array}{l}\text { IFT, and viscosity under EM } \\
\text { waves }\end{array}$ & 18.8 & $\begin{array}{l}\text { IFT reduction and viscosity were improved } \\
\text { more when EM waves were applied. }\end{array}$ & $\begin{array}{l}\text { It will be good to study further by varying the } \\
\text { crystal structure of the material. }\end{array}$ & [103] \\
\hline
\end{tabular}


Table 3. Cont.

\begin{tabular}{|c|c|c|c|c|c|}
\hline Nanoparticles & Scope of Study & EM Freq. (MHz) & Outcome & Remark & Ref. \\
\hline $\mathrm{ZnO} \& \mathrm{Fe}_{2} \mathrm{O}_{3}$ & Core flooding & & $\begin{array}{l}\text { Good recovery was achieved using a curve } \\
\text { antenna with magnetic feeders during nanofluid } \\
\text { suspensions. }\end{array}$ & $\begin{array}{l}\text { Electric signal strength using curve antenna } \\
\text { with magnetic feeders performed better than the } \\
\text { case without magnetic feeders. }\end{array}$ & [84] \\
\hline $\mathrm{Fe}_{2} \mathrm{O}_{3}-\mathrm{Al}_{2} \mathrm{O}_{3}$ & Nano flooding test & 13.6 & $\begin{array}{l}\text { The composite of hematite and magnetic NPs is } \\
\text { essential when irradiated with EM waves for } \\
\text { EOR. }\end{array}$ & $\begin{array}{l}\text { More investigation is required of the energy } \\
\text { activation fluids for the EOR application. }\end{array}$ & [77] \\
\hline $\begin{array}{c}\mathrm{Fe}_{3} \mathrm{O}_{4} / \mathrm{SiO}_{2} \& \\
\mathrm{TiO}_{2} / \mathrm{SiO}_{2}\end{array}$ & Sand pack flooding & - & $\begin{array}{c}\mathrm{Fe}_{3} \mathrm{O}_{4} / \mathrm{SiO}_{2} \& \mathrm{TiO}_{2} / \mathrm{SiO}_{2} \text { nanofluids increased } \\
\text { oil recovery by } 24 \text { and } 23 \% \text {, respectively. }\end{array}$ & $\begin{array}{l}\text { Varying pressure can influence and affect the } \\
\text { outcome of the oil recovery. }\end{array}$ & [89] \\
\hline $\mathrm{Fe}_{3} \mathrm{O}_{4}$ & Glass micromodel flooding & - & $\begin{array}{l}\text { Coating the surface of the NPs with citric acid } \\
\text { improved the IFT and wettability alteration. }\end{array}$ & $\begin{array}{l}\text { If the coated magnetic NPs are stimulated by } \\
\text { EM wave radiation, very good results are } \\
\text { expected to be discovered. }\end{array}$ & {$[90]$} \\
\hline
\end{tabular}




\section{Challenges}

The emancipated applications of dielectric and magnetic NPs for improving trapped oil from a reservoir cannot be overemphasized, and a lot of effort has been made and different analyses are still ongoing. However, several challenges still need to be addressed so that the work will be more productive, efficient, and significant. Some of the challenges are as follows:

I. Most of the experimental analysis using dielectric and magnetic nanofluids were laboratory-scale analysis, in the sense that they were conducted under ambient temperature and had no practical applicability.

II. Field application has shown that direct heating of the reservoir via radio frequency EM heating has been executed with an essential outcome by improving the heavy oils. Such fieldwork was conducted for the first time in 1992 in the USA, Canada, and Russia, despite the limited work in that regard. However, EM-assisted nanofluids remain a great challenge in field application because most of the NPs studied so far cannot withstand the harsh situation of the reservoir. This will lead to a situation whereby EM wave propagation in nanofluids will get disturbed and be worthless.

III. Another great challenge has to do with nanofluids responses under the influence of EM waves, which required potential computational techniques that demand numerical simulators that will be used to examine essential and analytical modeling that will provide accurate and perfect calculations concerning the heat disaffection and distribution to the reservoir. However, the success of the work is also accredited to the optimum selection and application of the required frequency and power needed by the experiment.

IV. The high cost of nanoparticles remains problematic, because a huge amount of NPs is required for oil and gas industrial operation.

\section{Future Outlook}

Despite the challenges mentioned, there are ways forward that can provide an improvement in the subject matter, which need to be done in the prospective analysis by addressing such critical challenges as briefly discussed here:

I. Reservoir conditions need to be taken into consideration while conducting experimental analysis in such a way that the laboratory experiment will comply with the field-scale applications. Consequently, proper selection of NPs that can withstand high temperature and high pressure is highly recommended for future analysis while conducting nanofluids flooding at reservoir temperatures, because most of the NPs are temperature sensitive. In addition to that, more nanofluids flooding experiments are required in an advanced manner, because the laboratory experiment is an output manifestation of the fieldwork.

II. One of the significant ways to improve ahead of the existing experiment of the NPs on EOR is by modifying the surface of the particles, as a result of which the NPs' properties can be altered towards the worthy and eligible standard for a particular analysis. This can be achieved by attaching an appropriate polymer/surfactant to the surface of the NPs. However, there is very limited work on that, despite the reasonable outcome displayed, which was why the influential effect of NPs surface modification concerning EOR is not well known and not fully understood. Moreover, polymers or surfactant coating on the surface of the NPs can provide an advanced level of improvement in the reservoir in different ways, such as improving sweep efficiency, solubility, and stability of the nanofluids, smoothness mobility of the fluids in a porous medium, temperature tolerance, etc., which in turn improve the EOR. The NPs type, size, and concentrations played a significant role in this regard. Furthermore, the proper selection of polymer/surfactant is the most important factor by considering some environmental features like temperature, pressure, salinity, etc. Otherwise, the wrong selection of an appropriate 
polymer/surfactant can lead to low recovery, and indeed it can be disadvantageous and extremely detrimental to the reservoir rocks, as they can block the reservoir rock pores.

III. It is recommended to make further investigations with regards to the theoretical and analytical modeling to make accurate calculations concerning the required heat and frequency that favors the reservoir situation. Moreover, creating proper nanosensors that will be injected in the reservoir is also required which could help in creating optimum, significant, and effective signals to be applied during the exercise for the attainment of appropriate goals of improving oil productivity. It is also a logical and good idea to investigate the possible situation in which the sensors embedded with NPs can be used in that regard.

IV. The high cost of the NPs issue can be tackled by improving the major sources of forming the particles, thereby creating innovative cheaper raw materials that are cost-effective, electromagnetic field responsive, and environmentally feasible.

\section{Conclusions}

The unique properties of the nanoparticles (NPs) and unprecedented development and progressiveness observed in the various application has made them become one of the most useful materials in modern science and technology. NPs played a decisive role in oil and gas industries, like drilling, refinery, transportation, moreover, employing them in oil production has been proposed and a lot of work has been done on that aspect with a profitable outcome for oil recovery better than the usual conventional process of oil production. This paper has specifically provided a critical review of a recently published experimental analysis using magnetic and dielectric NPs inform of EM assisted nanofluids for EOR. Significantly, providing comprehensive literature upon chemical flooding via EM assisted nanofluids is highly significant in enabling the researchers to make further improvements before the field application. Different characteristics of the NPs should be scrutinized before undertaking the chemical nano flooding for EOR, which include the type of NPs, particle size, concentrations, temperature tolerance, and injection rate. Recently, a lot of investigations have had a significant outcome for EOR prevail using metal oxide $\mathrm{NPs}$; the metal oxides employed so far for EOR are $\mathrm{ZnO}, \mathrm{TiO}_{2}, \mathrm{Al}_{2} \mathrm{O}_{3}, \mathrm{MgO}, \mathrm{ZrO}_{2}, \mathrm{CeO}_{2}$, and $\mathrm{Fe}_{2} \mathrm{O}_{3}$. However, $\mathrm{MgO}$ shows low recovery, and $\mathrm{CeO}_{2}$ is not very effective. Some of the negative constraints that inhibit the performance of the NPs in stability, solubility, and mobility in the reservoir can be minimized or eliminated by embedding the surface of the particles with a required surfactant or polymer; however, extra precautions need to be taken during the polymer/surfactant selection. The technical review has shown that anionic surfactant was found to have performed positively in recovering residual oil in a sandstone reservoir; moreover, a lot of progressive reports toward chemical EOR were equally observed while employing cationic and nonionic surfactant in a carbonate reservoir. Notably, the comparative concentration ratio between the surfactant and NPs has to be considered because the surfactant would cover a small portion of the particles at low concentrations. EM-assisted nanofluids have shown a promising result in recovering oil from porous media. Some mechanisms that determine EOR, like IFT reduction, wettability alteration, and fluids viscosity change, were reported to be effective, consistent, and substantial when EM-assisted nanofluids were used.

Author Contributions: Y.M.H.: writing original draft preparation; B.H.G.: funding, supervision, writing—review and editing; H.M.Z.: supervision, writing—review and editing; M.F.H.: writingreview and editing; M.A.: conceptualization; A.A.A.: visualization; K.H.: validation. All authors have read and agreed to the published version of the manuscript.

Funding: This research was funded by Universiti Teknologi PETRONAS, and Universitas Islamic Riau (UIR) through International Collaborative Research Fund UTP-UIR research grant (cost center 015-ME0-167).

Institutional Review Board Statement: Not applicable. 
Informed Consent Statement: Not applicable.

Data Availability Statement: Not applicable.

Acknowledgments: The authors express their gratitude for the financial support of this study by Universiti Teknologi PETRONAS (UTP) and Universitas Islamic Riau (UIR) research grant cost center 015-ME0-167. The authors would like to express their appreciation for providing an excellent research facilities.

Conflicts of Interest: The authors declare no conflict of interest.

\section{References}

1. Adam, A.A.; Dennis, J.O.; Al-Hadeethi, Y.; Mkawi, E.M.; Abdulkadir, B.A.; Usman, F.; Hassan, Y.M.; Wadi, I.A.; Sani, M. State of the Art and New Directions on Electrospun Lignin/Cellulose Nanofibers for Supercapacitor Application: A Systematic Literature Review. Polymers 2020, 12, 2884. [CrossRef] [PubMed]

2. Joonaki, E.; Ghanaatian, S. The Application of Nanofluids for Enhanced Oil Recovery: Effects on Interfacial Tension and Coreflooding Process. Pet. Sci. Technol. 2014, 32, 2599-2607. [CrossRef]

3. Abidin, A.; Puspasari, T.; Nugroho, W. Polymers for Enhanced Oil Recovery Technology. Procedia Chem. 2012, 4, 11-16. [CrossRef]

4. Sun, X.; Zhang, Y.; Chen, G.; Gai, Z. Application of Nanoparticles in Enhanced Oil Recovery: A Critical Review of Recent Progress. Energies 2017, 10, 345. [CrossRef]

5. Chang, H.; Zhang, Z.; Wang, Q.; Xu, Z.; Guo, Z.; Sun, H.; Cao, X.; Qiao, Q. Advances in Polymer Flooding and Alkaline/Surfactant/Polymer Processes as Developed and Applied in the People's Republic of China. J. Pet. Technol. 2006, 58, 84-89. [CrossRef]

6. Vargo, J.; Turner, J.; Bob, V.; Pitts, M.J.; Wyatt, K.; Surkalo, H.; Patterson, D. Alkaline-Surfactant-Polymer Flooding of the Cambridge Minnelusa Field. Soc. Pet. Eng. 1999. [CrossRef]

7. Ahmadi, Y.; Eshraghi, S.E.; Bahrami, P.; Hasanbeygi, M.; Kazemzadeh, Y.; Vahedian, A. Comprehensive Water-Alternating-Gas (WAG) injection study to evaluate the most effective method based on heavy oil recovery and asphaltene precipitation tests. J. Pet. Sci. Eng. 2015, 133, 123-129. [CrossRef]

8. Sun, X.; Dong, M.; Zhang, Y.; Maini, B.B. Enhanced heavy oil recovery in thin reservoirs using foamy oil-assisted methane huff-n-puff method. Fuel 2015, 159, 962-973. [CrossRef]

9. AlHomadhi, E.; Amro, M.; Almobarky, M. Experimental application of ultrasound waves to improved oil recovery during waterflooding. J. King Saud Univ. Eng. Sci. 2014, 26, 103-110. [CrossRef]

10. Sahni, A.; Kumar, M.; Knapp, R.B. Electromagnetic heating methods for heavy oil reservoirs. Soc. Pet. Eng. 2000. [CrossRef]

11. Ovalles, C.; Fonseca, A.; Lara, A.; Alvarado, V.; Urrecheaga, K.; Ranson, A.; Mendoza, H. Opportunities of downhole dielectric heating in venezuela: Three case studies involving medium, heavy and extra-heavy crude oil reservoirs. Soc. Pet. Eng. 2002. [CrossRef]

12. Fanchi, J.R. Feasibility of reservoir heating by electromagnetic irradiation. Soc. Pet. Eng. 1990. [CrossRef]

13. Cheraghian, G.; Hendraningrat, L. A review on applications of nanotechnology in the enhanced oil recovery part B: Effects of nanoparticles on flooding. Int. Nano Lett. 2016, 6, 1-10. [CrossRef]

14. Sheng, J.J. Modern Chemical Enhanced Oil Recovery: Theory and Practice; Gulf Professional Publishing: Houston, TX, USA, 2010.

15. Ali, J.A.; Kolo, K.; Manshad, A.K.; Mohammadi, A.H. Recent advances in application of nanotechnology in chemical enhanced oil recovery: Effects of nanoparticles on wettability alteration, interfacial tension reduction, and flooding. Egypt. J. Pet. 2018, 27, 1371-1383. [CrossRef]

16. Firozjaii, A.M.; Saghafi, H.R. Review on chemical enhanced oil recovery using polymer flooding: Fundamentals, experimental and numerical simulation. Petroleum 2020, 6, 115-122. [CrossRef]

17. Suleimanov, B.A.; Ismailov, F.; Veliyev, E. Nanofluid for enhanced oil recovery. J. Pet. Sci. Eng. 2011, 78, 431-437. [CrossRef]

18. Ogolo, N.A.; Olafuyi, O.A.; Onyekonwu, M.O. Enhanced Oil Recovery Using Nanoparticles. In Proceedings of the SPE Saudi Arabia Section Technical Symposium and Exhibition, Al-Khobar, Saudi Arabia, 8-11 April 2012. [CrossRef]

19. Zanganeh, P.; Ayatollahi, S.; Alamdari, A.; Zolghadr, A.; Dashti, H.; Kord, S. Asphaltene Deposition during $\mathrm{CO}_{2}$ Injection and Pressure Depletion: A Visual Study. Energy Fuels 2012, 26, 1412-1419. [CrossRef]

20. Borton, D.; Pinkston, D.S.; Hurt, M.R.; Tan, X.; Azyat, K.; Scherer, A.; Tykwinski, R.; Gray, M.; Qian, K.; Kenttämaa, H.I. Molecular Structures of Asphaltenes Based on the Dissociation Reactions of Their Ions in Mass Spectrometry. Energy Fuels 2010, 24, 5548-5559. [CrossRef]

21. Joonaki, E.; Buckman, J.; Burgass, R.; Tohidi, B. Water versus Asphaltenes; Liquid-Liquid and Solid-Liquid Molecular Interactions Unravel the Mechanisms behind an Improved Oil Recovery Methodology. Sci. Rep. 2019, 9, 1-13. [CrossRef]

22. Sheu, E.Y.; Mullins, O.C. Fundamentals and Applications; Springer: Berlin/Heidelberg, Germany, 1995.

23. Kazemzadeh, Y.; Parsaei, R.; Riazi, M. Experimental study of asphaltene precipitation prediction during gas injection to oil reservoirs by interfacial tension measurement. Colloids Surfaces A Physicochem. Eng. Asp. 2015, 466, 138-146. [CrossRef]

24. Tharanivasan, A.K.; Yarranton, H.W.; Taylor, S.D. Asphaltene Precipitation from Crude Oils in the Presence of Emulsified Water. Energy Fuels 2012, 26, 6869-6875. [CrossRef] 
25. Tavakkoli, M.; Chen, A.; Sung, C.-A.; Kidder, K.M.; Lee, J.J.; Alhassan, S.M.; Vargas, F.M. Effect of Emulsified Water on Asphaltene Instability in Crude Oils. Energy Fuels 2016, 30, 3676-3686. [CrossRef]

26. Aslan, S.; Firoozabadi, A. Effect of Water on Deposition, Aggregate Size, and Viscosity of Asphaltenes. Langmuir 2014, 30, 3658-3664. [CrossRef] [PubMed]

27. Hu, C.; Sabio, J.C.; Yen, A.; Joshi, N.; Hartman, R.L. Role of Water on the Precipitation and Deposition of Asphaltenes in Packed-Bed Microreactors. Ind. Eng. Chem. Res. 2015, 54, 4103-4112. [CrossRef]

28. Fakoya, M.F.; Shah, S.N. Emergence of nanotechnology in the oil and gas industry: Emphasis on the application of silica nanoparticles. Petroleum 2017, 3, 391-405. [CrossRef]

29. Kamyshny, A.; Magdassi, S. Aqueous dispersions of metallic nanoparticles: Preparation, stabilization and application. In Nanoscience: Colloidal and Interfacial Aspects; CRC Press: Boca Raton, FL, USA, 2010; pp. 747-778.

30. Sekoai, P.T.; Ouma, C.N.M.; Du Preez, S.P.; Modisha, P.; Engelbrecht, N.; Bessarabov, D.G.; Ghimire, A. Application of nanoparticles in biofuels: An overview. Fuel 2019, 237, 380-397. [CrossRef]

31. Riley, M.; Young, S.; Stamatakis, E.; Guo, Q.; Ji, L.; De Stefano, G.; Price, K.; Friedheim, J. Wellbore Stability in Unconventional Shales-The Design of a Nano-Particle Fluid. In Proceedings of the SPE Oil and Gas India Conference and Exhibition, Mumbai, India, 28-30 March 2012.

32. Wilson, M.; Kannangara, K.; Smith, G.; Simmons, M.; Raguse, B. Nanotechnology: Basic Science and Emerging Technologies; CRC Press: Boca Raton, FL, USA, 2002.

33. Khalil, M.; Jan, B.M.; Tong, C.W.; Berawi, M.A. Advanced nanomaterials in oil and gas industry: Design, application and challenges. Appl. Energy 2017, 191, 287-310. [CrossRef]

34. Negin, C.; Ali, S.; Xie, Q. Application of nanotechnology for enhancing oil recovery-A review. Petroleum 2016, 2, 324-333. [CrossRef]

35. Engeset, B. The Potential of Hydrophilic Silica Nanoparticles for EOR Purposes: A Literateur Review and an Experimental Study. Master's Thesis, Department of Petroleum Engineering and Applied Geophysics, Norwegian University of Science and Technology (NTNU), Trondheim, Norway, 2012.

36. Kazemzadeh, Y.; Shojaei, S.; Riazi, M.; Sharifi, M. Review on application of nanoparticles for EOR purposes: A critical review of the opportunities and challenges. Chin. J. Chem. Eng. 2019, 27, 237-246. [CrossRef]

37. Zhang, T.; Davidson, D.; Bryant, S.L.; Huh, C. Nanoparticle-stabilized emulsions for applications in enhanced oil recovery. Soc. Pet. Eng. 2010. [CrossRef]

38. Suleimanov, B.A.; Abbasov, H.F. Effect of copper nanoparticle aggregation on the thermal conductivity of nanofluids. Russ. J. Phys. Chem. A 2016, 90, 420-428. [CrossRef]

39. Ko, S.; Huh, C. Use of nanoparticles for oil production applications. J. Pet. Sci. Eng. 2019, 172, 97-114. [CrossRef]

40. Kumar, H.; Venkatesh, N.; Bhowmik, H.; Kuila, A. Metallic nanoparticle: A review. Biomed. J. Sci. Tech. Res. 2018, 4, 3765-3775. [CrossRef]

41. Shokrlu, Y.H.; Babadagli, T. Effects of Nano-Sized Metals on Viscosity Reduction of Heavy Oil/Bitumen During Thermal Applications. In Proceedings of the Canadian Unconventional Resources and International Petroleum Conference, Calgary, AB, Canada, 19-21 October 2010.

42. Rodríguez, J.A.; Fernández-García, M. Synthesis, Properties, and Applications of Oxide Nanomaterials; John Wiley \& Sons: Hoboken, NJ, USA, 2007.

43. Agista, M.N.; Guo, K.; Yu, Z. A State-of-the-Art Review of Nanoparticles Application in Petroleum with a Focus on Enhanced Oil Recovery. Appl. Sci. 2018, 8, 871. [CrossRef]

44. Bayat, A.E.; Junin, R.; Samsuri, A.; Piroozian, A.; Hokmabadi, M. Impact of Metal Oxide Nanoparticles on Enhanced Oil Recovery from Limestone Media at Several Temperatures. Energy Fuels 2014, 28, 6255-6266. [CrossRef]

45. Zaid, H.M.; Latiff, N.R.A.; Yahya, N.; Soleimani, H.; Shafie, A. Application of Electromagnetic Waves and Dielectric Nanoparticles in Enhanced Oil Recovery. J. Nano Res. 2013, 26, 135-142. [CrossRef]

46. Lee, K.C.; Bin Saipolbahri, Z.A.; Soleimani, H.; Zaid, H.M.; Guan, B.H.; Ching, D.L.C. Effect of Zinc Oxide Nanoparticle Sizes on Viscosity of Nanofluid for Application in Enhanced Oil Recovery. J. Nano Res. 2016, 38, 36-39. [CrossRef]

47. Iglauer, S.; Wu, Y.; Shuler, P.; Tang, Y.; Goddard, W.A. New surfactant classes for enhanced oil recovery and their tertiary oil recovery potential. J. Pet. Sci. Eng. 2010, 71, 23-29. [CrossRef]

48. Hendraningrat, L.; Li, S.; Torsaeter, O. A coreflood investigation of nanofluid enhanced oil recovery. J. Pet. Sci. Eng. 2013, 111, 128-138. [CrossRef]

49. Adil, M.; Lee, K.; Zaid, H.M.; Latiff, N.R.A.; Alnarabiji, M.S. Experimental study on electromagnetic-assisted ZnO nanofluid flooding for enhanced oil recovery (EOR). PLoS ONE 2018, 13, e0193518. [CrossRef]

50. Torsater, O.; Engeset, B.; Hendraningrat, L.; Suwarno, S. Improved Oil Recovery by Nanofluids Flooding: An Experimental Study. In Proceedings of the SPE Kuwait International Petroleum Conference and Exhibition, Society of Petroleum Engineers (SPE), Kuwait City, Kuwait, 10-12 December 2012.

51. Hendraningrat, L.; Torsæter, O. Metal oxide-based nanoparticles: Revealing their potential to enhance oil recovery in different wettability systems. Appl. Nanosci. 2015, 5, 181-199. [CrossRef]

52. Almahfood, M.; Bai, B. The synergistic effects of nanoparticle-surfactant nanofluids in EOR applications. J. Pet. Sci. Eng. 2018, 171, 196-210. [CrossRef] 
53. Arashiro, E.Y.; Demarquette, N.R. Use of the pendant drop method to measure interfacial tension between molten polymers. Mater. Res. 1999, 2, 23-32. [CrossRef]

54. Lee, K.; Adil, M.; Zaid, H.M.; Guan, B.H.; Soleimani, H.; Weis, M. Wettability, Interfacial Tension (IFT) and Viscosity Alteration of Nanofluids Under Electromagnetic (EM) Waves for Enhanced Oil Recovery (IFT) Applications. In Bioactive Natural Products for Pharmaceutical Applications; Springer Science and Business Media LLC: Berlin, Germany, 2018; pp. $305-311$.

55. Rezvani, H.; Riazi, M.; Tabaei, M.; Kazemzadeh, Y.; Sharifi, M. Experimental investigation of interfacial properties in the EOR mechanisms by the novel synthesized $\mathrm{Fe}_{3} \mathrm{O}_{4} @$ Chitosan nanocomposites. Colloids Surfaces A Physicochem. Eng. Asp. 2018, 544, 15-27. [CrossRef]

56. Moslan, M.S.; Sulaiman, W.R.W.; Ismail, A.R.; Jaafar, M.Z. Applications of aluminium oxide and zirconium oxide nanoparticles in altering dolomite rock wettability using different dispersing medium. Chem. Eng. Trans. 2017, 56, 1339-1344.

57. Ali, H.; Soleimani, H.; Yahya, N.; Khodapanah, L.; Sabet, M.; Demiral, B.M.; Hussain, T.; Adebayo, L.L. Enhanced oil recovery by using electromagnetic-assisted nanofluids: A review. J. Mol. Liq. 2020, 309, 113095. [CrossRef]

58. Esmaeilnezhad, E.; Le Van, S.; Chon, B.H.; Choi, H.J.; Schaffie, M.; Gholizadeh, M.; Ranjbar, M. An experimental study on enhanced oil recovery utilizing nanoparticle ferrofluid through the application of a magnetic field. J. Ind. Eng. Chem. 2018, 58, 319-327. [CrossRef]

59. Ali, J.A.; Kolo, K.; Manshad, A.K.; Stephen, K.D. Potential application of low-salinity polymeric-nanofluid in carbonate oil reservoirs: IFT reduction, wettability alteration, rheology and emulsification characteristics. J. Mol. Liq. 2019, 284, 735-747. [CrossRef]

60. Adil, M.; Zaid, H.M.; Chuan, L.K. Electromagnetically-induced change in interfacial tension and contact angle of oil droplet using dielectric nanofluids. Fuel 2020, 259, 116274. [CrossRef]

61. Bila, A.; Stensen, J.Å.; Torsæter, O. Experimental Investigation of Polymer-Coated Silica Nanoparticles for Enhanced Oil Recovery. Nanomaterials 2019, 9, 822. [CrossRef]

62. Negin, C.; Ali, S.; Xie, Q. Most common surfactants employed in chemical enhanced oil recovery. Petroleum 2017, 3, 197-211. [CrossRef]

63. ShamsiJazeyi, H.; Miller, C.A.; Wong, M.S.; Tour, J.M.; Verduzco, R. Polymer-coated nanoparticles for enhanced oil recovery. J. Appl. Polym. Sci. 2014, 131. [CrossRef]

64. Alvarez, N.J.; Anna, S.L.; Saigal, T.; Tilton, R.D.; Walker, L.M. Interfacial Dynamics and Rheology of Polymer-Grafted Nanoparticles at Air-Water and Xylene-Water Interfaces. Langmuir 2012, 28, 8052-8063. [CrossRef] [PubMed]

65. Dai, C.; Wang, S.; Li, Y.; Gao, M.; Liu, Y.; Sun, Y.; Zhao, M. The first study of surface modified silica nanoparticles in pressuredecreasing application. RSC Adv. 2015, 5, 61838-61845. [CrossRef]

66. Choi, S.K.; Son, H.A.; Kim, H.T.; Kim, J.W. Nanofluid Enhanced Oil Recovery Using Hydrophobically Associative Zwitterionic Polymer-Coated Silica Nanoparticles. Energy Fuels 2017, 31, 7777-7782. [CrossRef]

67. Zhao, M.; Gao, M.; Dai, C.; Li, Y.; Lv, W. The Study of a Novel Modified Silica Nanofluid for Pressure-Decreasing Application in the Ultra-Low Permeable Formation. In Proceedings of the SPE/IATMI Asia Pacific Oil \& Gas Conference and Exhibition; Society of Petroleum Engineers (SPE), Jakarta, Indonesia, 17-19 October 2017.

68. Wei, L.; Zhu, J.; Qi, J. Application of nano-nickel catalyst in the viscosity reduction of Liaohe extra-heavy oil by aqua-thermolysis. J. Fuel Chem. Technol. 2007, 35, 176-180.

69. Adil, M.; Zaid, H.M.; Chuan, L.K.; Latiff, N.R.A. Influence of electromagnetic waves on viscosity and electrorheology of dielectric nanofluids-scale-based approach. J. Teknol. 2016, 78. [CrossRef]

70. Karimi, A.; Fakhroueian, Z.; Bahramian, A.; Pour Khiabani, N.; Darabad, J.B.; Azin, R.; Arya, S. Wettability Alteration in Carbonates using Zirconium Oxide Nanofluids: EOR Implications. Energy Fuels 2012, 26, 1028-1036. [CrossRef]

71. Moslan, M.S.; Sulaiman, W.R.W.; Ismail, A.R.; Jaafar, M.Z.; Ismail, I. Wettability Alteration of Dolomite Rock Using Nanofluids for Enhanced Oil Recovery. Mater. Sci. Forum 2016, 864, 194-198. [CrossRef]

72. Shah, R.D. Application of Nanoparticle Saturated Injectant Gases for EOR of Heavy Oils. In Proceedings of the SPE Annual Technical Conference and Exhibition, New Orleans, LA, USA, 4-7 October 2009.

73. Ehtesabi, H.; Ahadian, M.M.; Taghikhani, V.; Ghazanfari, M.H. Enhanced Heavy Oil Recovery in Sandstone Cores Using TiO 2 Nanofluids. Energy Fuels 2014, 28, 423-430. [CrossRef]

74. Kasevich, R.; Price, S.; Faust, D.; Fontaine, M. Pilot testing of a radio frequency heating system for enhanced oil recovery from diatomaceous earth. Soc. Pet. Eng. 1994. [CrossRef]

75. Bera, A.; Babadagli, T. Status of electromagnetic heating for enhanced heavy oil/bitumen recovery and future prospects: A review. Appl. Energy 2015, 151, 206-226. [CrossRef]

76. Chhetri, A.B.; Islam, M.R. A Critical Review of Electromagnetic Heating for Enhanced Oil Recovery. Pet. Sci. Technol. 2008, 26, 1619-1631. [CrossRef]

77. Soleimani, H.; Latiff, N.R.A.; Yahya, N.; Zaid, H.M.; Sabet, M.; Guan, B.H.; Lee, K.C. Effect of Annealing Temperature on the Crystallization of Hematite-Alumina $\left(\mathrm{Fe}_{2} \mathrm{O}_{3}-\mathrm{Al}_{2} \mathrm{O}_{3}\right)$ Nanocomposite and its Influence in EOR Application. J. Nano Res. 2014, 29, 105-113. [CrossRef]

78. Yahya, N.; Kashif, M.; Nasir, N.; Akhtar, M.N.; Yusof, N.M. Cobalt Ferrite Nanoparticles: An Innovative Approach for Enhanced Oil Recovery Application. J. Nano Res. 2012, 17, 115-126. [CrossRef] 
79. Davidson, A.; Huh, C.; Bryant, S.L. Focused Magnetic Heating Utilizing Superparamagnetic Nanoparticles for Improved Oil Production Applications. In Proceedings of the SPE International Oilfield Nanotechnology Conference and Exhibition, Noordwijk, The Netherlands, 12-14 June 2012.

80. Soleimani, H.; Yahya, N.; Latiff, N.R.A.; Zaid, H.M.; Demiral, B.; Amighian, J. Novel Enhanced Oil Recovery Method Using $\mathrm{Co}^{2+}{ }_{x} \mathrm{Fe}^{2+}{ }_{1-x} \mathrm{Fe}^{3+}{ }_{2} \mathrm{O}^{4}$ as Magnetic Nanoparticles Activated by Electromagnetic Waves. J. Nano Res. 2013, 26, 111-116. [CrossRef]

81. Haroun, M.R.; Alhassan, S.M.; Ansari, A.A.; Al Kindy, N.A.M.; Sayed, N.A.; Kareem, B.A.A.; Sarma, H.K. Smart Nano-EOR Process for Abu Dhabi Carbonate Reservoirs. In Proceedings of the Abu Dhabi International Petroleum Conference and Exhibition, Abu Dhabi, UAE, 11-14 November 2012.

82. Zaid, H.M.; Adil, M.; Lee, K.; Latiff, N.R. Influence of Frequency-Dependent Dielectric Loss on Electrorheology of Surface Modified ZnO Nanofluids. In Proceedings of the IOP Conference Series: Materials Science and Engineering; IOP Publishing: Amsterdam, The Netherlands, 2018; Volume 350, p. 012014.

83. Latiff, N.R.A.; Yahya, N.; Zaid, H.M.; Demiral, B. Novel enhanced oil recovery method using dielectric zinc oxide nanoparticles activated by electromagnetic waves. In Proceedings of the 2011 National Postgraduate Conference; Institute of Electrical and Electronics Engineers (IEEE): New York, NY, USA, 2011; pp. 1-7.

84. Yahya, N.; Kashif, M.; Shafie, A.; Soleimani, H.; Zaid, H.M.; Latiff, N.R.A. Improved Oil Recovery by High Magnetic Flux Density Subjected to Iron Oxide Nanofluids. J. Nano Res. 2013, 26, 89-99. [CrossRef]

85. Yusmaniar, Y.; Hutomo, D.; Handoko, E.J.M. Electromagnetic wave absorbing properties of husk silica-based $\mathrm{SiO}_{2} / \mathrm{Fe}_{3} \mathrm{O}_{4} / \mathrm{UPR}$ composite. Mater. Sci. Eng. Conf. Ser. 2018, 434, 012081. [CrossRef]

86. Soleimani, H.; Latiff, N.R.A.; Yahya, N.; Zaid, H.M.; Sabet, M.; Lee, K.C.; Adil, M. Magnetization of Ferrofluid and its Influence on Improving Oil Recovery. Defect Diffusion Forum 2019, 390, 161-167. [CrossRef]

87. Zaid, H.M.; Azahar, W.W.; Soleimani, H.; Latiff, N.A.; Shafie, A.; Lee, K.C.; Beh, H. Effect of Nickel: Zinc Ratio in Nickel-ZincFerrite Nanoparticles as Surfactant on Recovery Efficiency in Enhanced Oil Recovery. J. Nano Res. 2014, 29, 115-120. [CrossRef]

88. Tarek, M. Investigating Nano-Fluid Mixture Effects to Enhance Oil Recovery. In Proceedings of the SPE Annual Technical Conference and Exhibition, Houston, TX, USA, 28-30 September 2015.

89. Kazemzadeh, Y.; Sharifi, M.; Riazi, M.; Rezvani, H.; Tabaei, M. Potential effects of metal oxide/SiO 2 nanocomposites in EOR processes at different pressures. Colloids Surfaces A Physicochem. Eng. Aspects. 2018, 559, 372-384. [CrossRef]

90. Divandari, H.; Hemmati-Sarapardeh, A.; Schaffie, M.; Ranjbar, M. Integrating synthesized citric acid-coated magnetite nanoparticles with magnetic fields for enhanced oil recovery: Experimental study and mechanistic understanding. J. Pet. Sci. Eng. 2019, 174, 425-436. [CrossRef]

91. Soleimani, H.; Latiff, N.R.A.; Yahya, N.; Sabet, M.; Khodapanah, L.; Kozlowski, G.; Chuan, L.K.; Guan, B.H. Synthesis and Characterization of Yttrium Iron Garnet (YIG) Nanoparticles Activated by Electromagnetic Wave in Enhanced Oil Recovery. J. Nano Res. 2016, 38, 40-46. [CrossRef]

92. Kazemzadeh, Y.; Dehdari, B.; Etemadan, Z.; Riazi, M.; Sharifi, M. Experimental investigation into $\mathrm{Fe}_{3} \mathrm{O}_{4} / \mathrm{SiO}_{2}$ nanoparticle performance and comparison with other nanofluids in enhanced oil recovery. Pet. Sci. 2019, 16, 578-590. [CrossRef]

93. Vekas, L. Magnetic nanofluids properties and some applications. Rom. J. Phys. 2004, 49, 707-721.

94. Baig, M.K.; Soleimani, H.; Yahya, N. Domain wall motion and Barkhausen effect in magnetic nanoparticles for EOR applications. In Proceedings of the 4th International Conference on Fundamental and Applied Sciences (Icfas2016); AIP Publishing: College Park, MD, USA, 2016; Volume 1787, p. 50015.

95. Mukhametshina, A.; Martynova, E. Electromagnetic heating of heavy oil and bitumen: A review of experimental studies and field applications. J. Pet. Eng. 2013. [CrossRef]

96. Adil, M.; Zaid, H.M.; Chuan, L.K.; Latiff, N.R.A. Effect of EM propagation medium on electrorheological characteristics of dielectric nanofluids. J. Dispers. Sci. Technol. 2016, 38, 570-576. [CrossRef]

97. Primo, V.A.; Pérez-Rosa, D.; Garcia, B.; Cabanelas, J.C. Evaluation of the Stability of Dielectric Nanofluids for Use in Transformers under Real Operating Conditions. Nanomaterials 2019, 9, 143. [CrossRef]

98. Ali, A.M.; Yahya, N.; Qureshi, S. Interactions of ferro-nanoparticles (hematite and magnetite) with reservoir sandstone: Implications for surface adsorption and interfacial tension reduction. Pet. Sci. 2020, 17, 1037-1055. [CrossRef]

99. Kothari, N.; Raina, B.; Chandak, K.B.; Iyer, V.; Mahajan, H.P. Application Of Ferrofluids For Enhanced Surfactant Flooding In IOR. In Proceedings of the SPE EUROPEC/EAGE Annual Conference and Exhibition, Barcelona, Spain, 14-17 June 2010.

100. Chuan, L.K.; Guan, B.H.; Yusuf, Y.; Zainuddin, A.A.; Auni, N. Interfacial Tension and Contact Angle Alteration of Nanofluids by using Lanthanum Substituted Manganese-Zinc Ferrite Nanoparticles. DJNB 2019, 14, 1-5.

101. Lau, Z.Y.; Lee, K.; Soleimani, H.; Beh, H.G. Experimental Study of Electromagnetic-Assisted Rare-Earth Doped Yttrium Iron Garnet (YIG) Nanofluids on Wettability and Interfacial Tension Alteration. Energies 2019, 12, 3806. [CrossRef]

102. Lee, K.C.; Sukri, M.N.M.; Guan, B.H.; Zaid, H.M.; Soleimani, H. Interfacial Tension and Viscosity Alteration of Samarium Doped Yttrium Iron Garnet (YIG) Nanofluid under the Presence of Electromagnetic Waves. Defect Diffus. Forum 2019, 390, 64-70. [CrossRef]

103. Lee, K.; Shuhaili, F.M.; Zaid, H.M.; Guan, B.H. Neodymium (Nd) Doped Yttrium Iron Garnet (YIG) Nanofluid Activated By Electromagnetic Waves for Enhanced Oil Recovery (EOR). J. Phys. Conf. Ser. 2018, 1123, 012011. [CrossRef] 
104. Izadi, N.; Koochi, M.M.; Amrollahi, A.; Pourkhalil, M. Investigation of functionalized polyelectrolyte polymer-coated $\mathrm{Fe}_{3} \mathrm{O}_{4}$ nanoparticles stabilized in high salinity brine at high temperatures as an EOR agent. J. Pet. Sci. Eng. 2019, 178, 1079-1091. [CrossRef]

105. Chang, H.; Chang, Y.-C. Fabrication of $\mathrm{Al}_{2} \mathrm{O}_{3}$ nanofluid by a plasma arc nanoparticles synthesis system. J. Mater. Process. Technol. 2008, 207, 193-199. [CrossRef]

106. Tsuzuki, T.; McCormick, P.G. Mechanochemical synthesis of nanoparticles. J. Mater. Sci. 2004, 39, 5143-5146. [CrossRef]

107. Hafshejani, L.D.; Tangsir, S.; Koponen, H.; Riikonen, J.; Karhunen, T.; Tapper, U.; Lehto, V.-P.; Moazed, H.; Naseri, A.A.; Hooshmand, A.; et al. Synthesis and characterization of Al2O3 nanoparticles by flame spray pyrolysis (FSP)—Role of Fe ions in the precursor. Powder Technol. 2016, 298, 42-49. [CrossRef]

108. Ali, H.; Soleimani, H.; Yahya, N.; Lorimer, S.; Sabet, M.; Demiral, B.M.R.; Adebayo, L.L. Absorption of electromagnetic waves in sandstone saturated with brine and nanofluids for application in enhanced oil recovery. J. Taibah Univ. Sci. 2020, 14, 217-226. [CrossRef]

109. Wen, W.; Huang, X.; Yang, S.; Lu, K.; Sheng, P. The giant electrorheological effect in suspensions of nanoparticles. Nat. Mater. 2003, 2, 727-730. [CrossRef]

110. Binks, B.P. Particles as surfactants—similarities and differences. Curr. Opin. Colloid Interface Sci. 2002, 7, 21-41. [CrossRef]

111. Gupta, A.K.; Basu, S. Deformation of an oil droplet on a solid substrate in simple shear flow. Chem. Eng. Sci. 2008, 63, 5496-5502. [CrossRef]

112. Cui, M.; Emrick, T.; Russell, T.P. Stabilizing Liquid Drops in Nonequilibrium Shapes by the Interfacial Jamming of Nanoparticles. Science 2013, 342, 460-463. [CrossRef] [PubMed]

113. Zaid, H.M.; Adil, M.; Chuan, L.K.; Latiff, N.R.A. Stability and electrorheology of ZnO nanofluids in the presence of anionic surfactants. In Proceedings of the 4th International Conference on Fundamental and Applied Sciences (Icfas2016); AIP Publishing: College Park, MD, USA, 2016; Volume 1787, p. 050007.

114. Zaid, H.M.; Yahya, N.; Latiff, N.R.A. The Effect of Nanoparticles Crystallite Size on the Recovery Efficiency in Dielectric Nanofluid Flooding. J. Nano Res. 2012, 21, 103-108. [CrossRef] 